\title{
Closed System Step Etching of CI chondrite Ivuna reveals primordial noble gases in the HF-solubles
}

My E. I. Riebe ${ }^{a^{*}}$, Henner Busemann ${ }^{\mathrm{a}}$, Rainer Wieler ${ }^{\mathrm{a}}$, Colin Maden ${ }^{\mathrm{a}}$

${ }^{a}$ ETH Zurich, Institute of Geochemistry and Petrology, Clausiusstrasse 25, 8092 Zurich, Switzerland

\author{
*Corresponding author \\ Email: mriebe@carnegiescience.edu \\ phone: +1 (202) 478-8476 \\ fax: $+1(202) 478-8820$
}

Current address: Carnegie Institution of Washington, Department of Terrestrial Magnetism, 5241 Broad Branch Rd. NW, Washington DC 20015-1305, USA

Second revised version, submitted to Geochimica et Cosmochimica Acta, Jan 302017 


\section{Abstract}

We analyzed all the noble gases in HF-soluble phases in the CI chondrite Ivuna by in-vacuum gas release using the "Closed System Step Etching" (CSSE) technique, which allows for direct noble gas measurements of acid-soluble phases. The main motivation was to investigate if there are primordial noble gases in HF-soluble phases in Ivuna, something that has not been done before in CI chondrites, as most primordial noble gases are known to reside in HF-resistant phases. The first steps under mild etching released $\mathrm{He}, \mathrm{Ne}$, and Ar with solar-like elemental and isotopic compositions, confirming that Ivuna contains implanted solar wind (SW) noble gases acquired in the parent body regolith. The SW component released in some etch steps was elementally unfractionated. This is unusual as trapped SW noble gases are elementally fractionated in most meteoritic material. In the intermediate etch steps under slightly harsher etching, cosmogenic noble gases were more prominent than SW noble gases. The HF-soluble portion of Ivuna contained primordial $\mathrm{Ne}$ and $\mathrm{Xe}$, that was most visible in the last etch steps after all cosmogenic and most SW gases had been released. The primordial Ne and Xe in the HF-solubles have isotopic and elemental ratios readily explained as a mixture of the two most abundant primordial noble gas components in Ivuna bulk samples: HL and Q. Only small fractions of the total HL and $\mathrm{Q}$ in Ivuna were released during CSSE analysis; $\sim 3 \%$ of ${ }^{20} \mathrm{Ne}_{\mathrm{HL}}$ and $\sim 4 \%$ of ${ }^{132} \mathrm{Xe}_{\mathrm{Q}}$. $\mathrm{HL}$ is known to reside in nanodiamond-rich separates and Q-gases are most likely carried by a carbonaceous phase known as phase Q. Q-gases were likely released from an HF-soluble portion of phase Q. However, nanodiamonds might not be the source of the HL-gases released upon etching, since nanodiamond-rich separates are very HF-resistant and the less tightly bound nanodiamond component P3 was not detected. 


\section{Introduction}

Since the first discovery of nucleosynthetic anomalies in meteorites, noble gases have continued to be of great importance in isotopic anomaly studies (e.g., Ott, 2014). The search for the carrier phases of noble gas anomalies in meteorites led to the discovery of presolar nanodiamonds, $\mathrm{SiC}$, and graphite (e.g., Bernatowicz et al., 1987; Lewis et al., 1987; Amari et al., 1990). In addition to the noble gas components carried by presolar grains, the elusive and widespread Q-component, carried by an unidentified phase known as phase Q, has received a lot of attention (e.g., Lewis et al., 1975; Huss et al., 1996; Busemann et al., 2000; Marrocchi et al., 2015).

A summary of all the noble gas components discussed in this paper is given in Table 1. A noble gas component has a distinct noble gas composition and is sometimes associated with a specific process or a specific carrier. Primordial noble gases were incorporated into their carriers either prior to Solar System formation, as is the case for presolar grains, or, during Solar System formation as could be the case for phase Q (Ozima et al., 1998). For a more detailed description of the origin and characteristics of primordial noble gas components the reader is referred to the review by Ott (2014). Meteorites also contain noble gases formed in situ; cosmogenic noble gases which are formed by nuclear reactions induced primarily by galactic cosmic rays and radiogenic noble gases formed by radioactive decay. In addition the solar wind (SW), emitted from the sun, contains noble gases which are incorporated into the top nanometers of grains when exposed in interplanetary space, e.g., on the surface of an asteroidal regolith.

Phase Q, presolar nanodiamonds, $\mathrm{SiC}$, and graphite are predominantly $\mathrm{HF} / \mathrm{HCl}$-resistant phases, which together make up a tiny fraction of the sample mass, $<0.01 \%$, but nonetheless contain the majority of the primordial noble gases in meteorites (e.g., Lewis et al., 1975; Bernatowicz et al., 1987; Lewis et al., 1987; Zinner et al., 1987; Amari et al., 1990; Amari et al., 
1994). As a consequence, primordial noble gas research has focused on preparing and analyzing $\mathrm{HF} / \mathrm{HCl}$-resistant residues. Primordial noble gases, which might be present in phases dissolved by $\mathrm{HF}$ and $\mathrm{HCl}$ treatment during preparation of such residues, the "solubles", have received less attention (Ott, 2014). Early work on noble gases in solubles was done by subtracting the gas concentrations of $\mathrm{HF} / \mathrm{HCl}-$ resistant residues from those of bulk measurements, a technique associated with large uncertainties due to the small gas amounts in the solubles relative to those in the $\mathrm{HF} / \mathrm{HCl}$-resistant phases (e.g., Alaerts et al., 1979a,b; Matsuda et al., 1980; Schelhaas et al., 1990). These uncertainties can be circumvented by using the "Closed System Step Etching" (CSSE) gas extraction technique, by which the sample is dissolved online in the high vacuum system, resulting in direct measurements of acid-soluble phases (Wieler et al., 1986; Busemann et al., 2000; Busemann et al., 2003a; Christen and Busemann, 2004). There are several advantages of the CSSE technique compared to other techniques when studying noble gases in soluble phases: (i) it is possible to target exclusively the soluble phases and analyze these undisturbed from the usually more abundant noble gases in the insoluble phases, (ii) the isotopic ratios can be measured accurately, (iii) the sample is analyzed in steps, which makes it easier to disentangle different components that are present in the soluble material in meteorites, and (iv) the gas release occurs at low temperatures, minimizing diffusion effects and reducing the blank. In general, the step etching attacks the grains from the outside inwards, releasing gases that are present on the surface of grains first and successively etching deeper portions of the grains. In addition, phases that are more susceptible to the acid are opened before phases that are less so.

Despite the large potential of studying primordial noble gases in bulk meteorites using CSSE, only bulk samples of E chondrites and one CV chondrite have been analyzed in this way so far (Busemann et al., 2003a; Christen and Busemann, 2004; Clay et al., 2012; King et al., 2013).The focus of this study is the examination of the noble gas content in HF-solubles of the CI 
chondrite Ivuna. The major motivation is to investigate if any HF-soluble phases containing primordial noble gases are present in this meteorite. In addition to potential primordial noble gases we expected to find large amounts of cosmogenic, radiogenic and SW noble gases; these gases are present in the silicate grains, which are dissolved by HF. Primordial gases could be associated with presolar grains or phase Q.

As has research on primordial noble gases, so too have isotopic studies and other work on presolar grains for a long time focused on $\mathrm{HF}-\mathrm{HCl}$ resistant grains. However, over the last 20 years acid-soluble presolar silicate and oxide grains have been detected, and hundreds of such grains carrying nucleosynthetic anomalies in oxygen and silicon have been studied (e.g., Nittler et al., 1994; Nguyen and Zinner, 2004; presolar database: Hynes and Gyngard, 2009). The O and Si nucleosynthetic anomalies in these grains suggest that they may also carry primordial noble gases. If so, the noble gases in the presolar silicate and oxide grains could help to further constrain their origin. In addition, association of noble gas anomalies with anomalies in other elements could improve understanding of the nucleosynthesis of these noble gas components. Presolar silicates are, as all silicates, easily destroyed when treated with HF, although some silicates could survive HF treatment if coated by organic macromolecular matter (c.f., Aléon et al. 2005). However, presolar oxides generally survive treatment with $\mathrm{HF} / \mathrm{HCl}$ (Nittler et al., 1994). Isotopic anomalies for different elements have also been discovered in leachates of CI and CM chondrites. Some, but not all of these anomalies may be explained by the presence of presolar SiC (Dauphas et al., 2002; Schönbächler et al., 2005; Reisberg et al., 2009; Hidaka and Yoneda, 2011; Paton et al., 2013).

CI chondrites have high concentrations of primordial noble gases (Huss et al., 1996, 2003). Earlier noble gas work on the CI chondrite Ivuna (Stauffer, 1961; Black and Pepin, 1969; 
Mazor et al., 1970; Black, 1972) showed that this meteorite contains significant amounts of primordial noble gas components such as Ne-E (carried by presolar SiC and graphite), HL (carried by nanodiamond-rich residues) and Q (carried by phase Q; see Table 1). In addition to the primordial components, the bulk measurements also show that Ivuna could contain some solar wind, based on ${ }^{4} \mathrm{He} /{ }^{20} \mathrm{Ne}$ ratios of $\sim 300$ and ${ }^{3} \mathrm{He} /{ }^{4} \mathrm{He}$ ratios of $3.11-5.81 \times 10^{-4}$ (Stauffer, 1961; Black and Pepin, 1969; Mazor et al., 1970; Black, 1972). By analyzing bulk material from Ivuna with CSSE using HF we are able to better characterize the noble gases in the HF-solubles of this meteorite. If the HF-solubles of Ivuna contain primordial noble gases, as we might expect from presolar grain research, then the CSSE technique is the most promising technique to detect those.

\section{Material and Methods}

The Closed System Step Etching (CSSE) extraction line has been described in detail elsewhere (Wieler et al., 1986; Benkert, 1989; Benkert et al., 1993; Signer et al., 1993; Busemann et al., 2000). In summary, the noble gases are extracted from the sample by etching it online in the high vacuum system with an acid, in this case concentrated HF. The line consists of two containers separated by a valve, one that contains the sample and one that contains the acid. All parts of the line in contact with the acid are made of gold or platinum. After loading, the acid was first degassed from atmospheric noble gases by several steps of heating and cooling. Atmospheric gases adsorbed to the grain surfaces were also reduced by pre-heating the sample to $80{ }^{\circ} \mathrm{C}$ for $\sim 50$ hours.

In this experiment all stable isotopes of $\mathrm{He}, \mathrm{Ne}, \mathrm{Ar}, \mathrm{Kr}$, and $\mathrm{Xe}$ in a $120 \mathrm{mg}$, gently crushed bulk sample (maximum grain size $\sim 1 \mathrm{~mm}$ ) from Ivuna were analyzed using $1.5 \mathrm{ml}$ of 
concentrated HF. The etching was done stepwise. The details of the etch conditions of the individual steps are given in Table 2. In the first 12 steps the sample was exposed to acid vapor for increasing times, in the succeeding 6 steps (steps 13 to 18) the sample was etched by transferring increasing amounts of acid into the sample volume. Acid was transferred to the sample volume by cooling the sample to $-15^{\circ} \mathrm{C}$ and keeping the acid at room temperature for increasing lengths of time. At step 19 the remaining acid was transferred to the sample volume at $-60{ }^{\circ} \mathrm{C}$, a temperature low enough to slow etching greatly and to minimize attendant gas release (Table 2). This step is thus not considered in the data discussion. In steps 20 to 27 etching times and temperature were successively increased. Before the gas was expanded to the mass spectrometer and measured, the acid was cooled to reduce the vapor pressure and protect the instrument. The total duration of the etch run was two months.

Chemically active gases, including HF vapor, were removed using a cold trap at -50 to -60 ${ }^{\circ} \mathrm{C}$ and a series of getters; one getter filled with $\mathrm{CaO}$ powder, three getters filled with commercial $\mathrm{Zr}-\mathrm{V}-\mathrm{Fe}$ pellets (ST707 SAES ${ }^{\mathrm{TM}}$ ) held at $280^{\circ} \mathrm{C}$ and three $\mathrm{Zr}-\mathrm{V}-\mathrm{Fe}$ cartridge getters working at different temperatures (ST172 SAESTM). The cleaned noble gases were analyzed in three batches: $\mathrm{He}$ and $\mathrm{Ne}$, Ar, and $\mathrm{Kr}$ and $\mathrm{Xe}$. Helium and Ne were separated from the heavy noble gases by freezing $\mathrm{Ar}, \mathrm{Kr}$, and $\mathrm{Xe}$ to an activated charcoal cooled with liquid nitrogen. Argon was subsequently separated from $\mathrm{Kr}$ and $\mathrm{Xe}$ by freezing $\mathrm{Kr}$ and $\mathrm{Xe}$ to a cold trap kept at $-125^{\circ} \mathrm{C}$. Typically, about $10 \%$ of the Ar was left in the $\mathrm{Kr}$ and $\mathrm{Xe}$ batch and $2 \%$ of the $\mathrm{Kr}$ and $0.5 \%$ of the Xe were in the Ar batch. This has been corrected for in the presented data. The noble gases were analyzed by static noble gas mass spectrometry using an in-house built sector field mass spectrometer equipped with a Baur-Signer ion source, a secondary electron multiplier for ion counting, and a Faraday cup. Sensitivity and mass fractionation in the mass spectrometer were determined by regular analyses of calibration gas mixtures of known amounts and isotopic ratios 


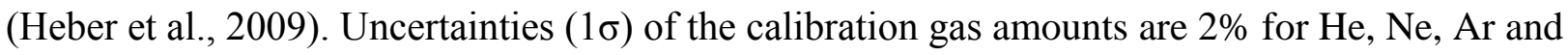
$5 \%$ for $\mathrm{Kr}$ and $\mathrm{Xe}$ (Heber et al., 2009) and are included in the uncertainties of gas concentrations given in the tables. Isotopic ratios in our calibration gas are air-like with the exception of He, which is strongly enriched in ${ }^{3} \mathrm{He}$ relative to air. The signal at $19 \mathrm{amu}$ (fluorine) was monitored and no increase during sample analyses was ever detected, showing that the clean-up procedure efficiently removed all traces of $\mathrm{HF}$, potentially interfering on ${ }^{20} \mathrm{Ne}$ and harming the system.

Blanks of the system were measured frequently and corrected for. Adopted uncertainties of blank corrections are the standard deviations of all blanks relevant for a given etch step. Contributions to uncertainties on isotopic ratios from the blank never exceed $1 \%$ for $\mathrm{He}, \mathrm{Ne}$, and Ar and is in most cases less than $2 \%$ for $\mathrm{Kr}$ and $\mathrm{Xe}$ (except for the very small step 2, see Table 3 ). These uncertainties are included in the reported isotopic ratios.

In addition to the CSSE experiment, one $13 \mathrm{mg}$ aliquot of the crushed Ivuna sample was analyzed with one step pyrolysis in a furnace. This sample is in the following referred to as the bulk sample. The bulk sample was wrapped in Al-foil and pre-heated in vacuum at $100{ }^{\circ} \mathrm{C}$ for $\sim 24 \mathrm{~h}$ to reduce atmospheric contamination. A blank was analyzed by dropping an empty Al-foil piece in the oven and analyzed following the same protocol as the sample measurement. The sample was degassed at $\sim 1700{ }^{\circ} \mathrm{C}$ and analyzed in the same way as described for the CSSE technique above, with the exception that fewer getters were used (one $\mathrm{Zr}-\mathrm{V}$-Fe pellets getter held at $280{ }^{\circ} \mathrm{C}$ and two $\mathrm{Zr}-\mathrm{V}$-Fe cartridge getters). A re-extraction step at a slightly higher temperature yielded less than $0.5 \%$ of the gas $(\mathrm{He}-\mathrm{Xe})$ released in the main degassing step. Argon-38 was not measured accurately in the bulk sample due to a very large ${ }^{40} \mathrm{Ar}$ peak. 


\section{Results}

\subsection{CSSE analysis}

To facilitate the interpretation of the CSSE data the etch run is divided into three parts. This division is based on the isotopic and elemental composition of the individual etch steps, reflecting variations in the dominating noble gas components during the etch run. The three parts also largely correspond to major changes in etching conditions.

\subsubsection{First part of the CSSE analysis (steps 1-10): dominated by SW}

In the first part of the etch run (steps 1-10) the gases were released by mild vapor etching (Table 2). In these steps predominantly solar-like gases were released, characterized by SW-like He and Ne isotopic ratios (Figs. 1 and 2) as well as SW-like ${ }^{4} \mathrm{He} /{ }^{20} \mathrm{Ne},{ }^{4} \mathrm{He} /{ }^{36} \mathrm{Ar}$, and ${ }^{20} \mathrm{Ne} /{ }^{36} \mathrm{Ar}$ elemental ratios (Figs. 3 and 4). The data, thus, suggest that these steps predominantly released SW noble gases implanted into the grain surfaces, as is commonly observed in CSSE analyses of SW-rich regolithic meteorites (e.g., Murer et al., 1997; Becker et al., 1998; Wieler et al., 2000). Some 75$90 \%$ of the total ${ }^{4} \mathrm{He}$ and ${ }^{20,22} \mathrm{Ne}$ released in the entire CSSE run was set free in the first 10 etch steps, hence, most of the $\mathrm{He}$ and $\mathrm{Ne}$ in the entire etch run was SW-like. In contrast, only about $20-35 \%$ of the ${ }^{36} \mathrm{Ar},{ }^{84} \mathrm{Kr}$, and ${ }^{132} \mathrm{Xe}$ released in the whole etch run was measured in these first 10 steps, corresponding to only a few percent of the gas concentrations released in bulk pyrolysis (section 3.2). About $50 \%$ of the total ${ }^{21} \mathrm{Ne}_{\cos }$ and $60 \%$ of the ${ }^{3} \mathrm{He}_{\cos }$ in the etch run was released in part 1 (Fig. 5b), indicating that a sizable volume was etched in the first 10 etch steps as cosmogenic noble gases are present in the bulk of grains, whereas the SW gases reside near the grain surfaces.

In Fig. $3 \mathrm{a}{ }^{4} \mathrm{He} /{ }^{36} \mathrm{Ar}$ is plotted against ${ }^{20} \mathrm{Ne} /{ }^{36} \mathrm{Ar}$. Steps 5-10 fall near or on a mixing line between a composition with low ${ }^{4} \mathrm{He} /{ }^{36} \mathrm{Ar}$ and ${ }^{20} \mathrm{Ne} /{ }^{36} \mathrm{Ar}$ ratios and $\mathrm{SW}$ with high ${ }^{4} \mathrm{He} /{ }^{36} \mathrm{Ar}$ and 
${ }^{20} \mathrm{Ne} /{ }^{36} \mathrm{Ar}$ ratios. This is also illustrated in Fig 4, where the trapped ${ }^{4} \mathrm{He} /{ }^{20} \mathrm{Ne}$ ratio is shown. Especially steps 6-10 have ${ }^{4} \mathrm{He} /{ }^{20} \mathrm{Ne}$ ratios remarkably close to the $\mathrm{SW}$ value of 656 as measured in a Genesis mission target (Heber et al., 2012). This is unusual as in most SW-containing samples the SW is fractionated both elementally and isotopically relative to unfractionated SW as measured in Genesis targets, favoring the heavy isotopes (e.g., Grimberg et al., 2006). Lower than $\mathrm{SW}{ }^{4} \mathrm{He} /{ }^{20} \mathrm{Ne}$ ratios are observed in the first etch steps of the Ivuna sample (Fig. 4; $\left({ }^{4} \mathrm{He} /{ }^{20} \mathrm{Ne}\right)_{\mathrm{tr}}=62-559$ in steps 1-5). This is also illustrated in Fig. 3 in which data from steps 1-4 plot below a mixing line between $\mathrm{SW}$ and the composition with low ${ }^{4} \mathrm{He} /{ }^{36} \mathrm{Ar}$ and ${ }^{20} \mathrm{Ne} /{ }^{36} \mathrm{Ar}$ ratios.

Isotopic compositions of both $\mathrm{He}$ and $\mathrm{Ne}$ released in steps $1-10$ are close to SW, confirming the evidence from the elemental ratios that most of the He and Ne released in the first part of the etch run is SW. The ${ }^{3} \mathrm{He} /{ }^{4} \mathrm{He}$ ratio in the first 9 steps varies between $3.54 \times 10^{-4}$ and $4.15 \times 10^{-4}$, slightly below the SW value of $4.64 \times 10^{-4}$ (Heber et al., 2009). The higher value in step $10\left({ }^{3} \mathrm{He} /{ }^{4} \mathrm{He}=4.51 \times 10^{-4}\right)$ presumably indicates that this step contains some cosmogenic He, as the following etch steps show a clear cosmogenic signal in He (Fig. 2). A large contribution of SW-like Ne was also seen in part 1 (Fig. 1). The data points of all 10 steps of part 1 of the etch run but also steps $11,14,15,17$, and 20 fall on an almost perfect mixing line between fSW (fractionated SW) and the cosmogenic component. Excluding steps 1 and 2, which may show small contributions of atmospheric Ne, a linear regression through these steps (adjusted R-Square $=0.99)$ gives a fSW value for ${ }^{20} \mathrm{Ne} /{ }^{22} \mathrm{Ne}$ of $12.25 \pm 0.34$ (assuming $\left({ }^{21} \mathrm{Ne} /{ }^{22} \mathrm{Ne}\right)$ Sw to be 0.0295 ) and $\left({ }^{21} \mathrm{Ne} /{ }^{22} \mathrm{Ne}\right)_{\cos }=0.83 \pm 0.02\left(\right.$ assuming $\left.\left({ }^{20} \mathrm{Ne} /{ }^{22} \mathrm{Ne}\right)_{\cos }=0.80\right)$. About $90 \%$ of all the ${ }^{20} \mathrm{Ne}_{\mathrm{fSw}}$ and $\sim 50 \%$ of the ${ }^{21} \mathrm{Ne}_{\mathrm{cos}}$ in the etch run is released in the first 10 etch steps (Fig. 5b). 
The ${ }^{36} \mathrm{Ar} /{ }^{38} \mathrm{Ar}$ ratio indicates a predominantly SW-like Ar contribution in most steps of the first part of the etch run (Fig. 6). Steps 1-8 have ${ }^{36} \mathrm{Ar} /{ }^{38} \mathrm{Ar}$ ratios between 5.43-5.62. This range is higher than the $Q$ value of $5.34 \pm 0.02$ (Busemann et al., 2000) and the atmospheric value of 5.32, and for most steps within uncertainty of the SW value of $5.47 \pm 0.01$ (Heber et al., 2009). The slightly lower values of steps 9 and 10 (Fig. 6) indicate that these steps likely contain small amounts of cosmogenic Ar similar to He and Ne, since the following etch steps in part 2 show a clear cosmogenic Ar signal.

Xenon in part 1 of the etch run is generally consistent with a mixture of Q, or possibly P3, and air, as seen in Fig. 7a. Xenon-P3 (primordial component carried by presolar nanodiamonds, Table 1) and Xe-Q have similar isotopic compositions and, as justified in the Discussion, we will mainly discuss the primordial $\mathrm{Xe}$ as $\mathrm{Xe}-\mathrm{Q}$. The measured isotopic composition can roughly be explained with a mixture of $20 \%$ Q or P3 and $80 \%$ air based on ${ }^{132}$ Xe. The atmospheric Xe could be remnant gas dissolved in the acid, Xe adsorbed to the surfaces of the sample, or Xe incorporated into secondary minerals which formed during the residence time of Ivuna on Earth. Some of the first 10 etch steps showed enrichment in ${ }^{129} \mathrm{Xe}$ relative to Q, P3 or air (Fig. 8). Xenon-129 enrichment in meteorites results from the decay of ${ }^{129} \mathrm{I}$, a now extinct isotope which was present during the formation of the Solar System (Reynolds, 1960). The concentration of radiogenic $\left({ }^{129} \mathrm{Xe}_{\mathrm{rad}}\right)$, as shown in Fig. 5, was determined based on the average mixture of air and $\mathrm{Q}$ for the different parts of the etch run (c.f. Fig. 2). About $30 \%$ of the ${ }^{129} \mathrm{Xe}_{\mathrm{rad}}$ in the etch run as a whole was released in part 1 . The ${ }^{129} \mathrm{Xe} /{ }^{132} \mathrm{Xe}$ ratio is variable between steps, probably reflecting the attack of individual grains or clusters of grains rich in iodine. Some steps contained major fractions of the radiogenic ${ }^{129} \mathrm{Xe}$, e.g., step 10 , which contained $\sim 15 \%$ of the total ${ }^{129} \mathrm{Xe}_{\text {rad }}$ in the etch run (Fig. 5). 


\subsubsection{Second part of the CSSE analysis (steps 11-20): dominated by cosmogenic gases}

The second part of the etch run (steps 11-20) essentially corresponds to the steps in which HF was transferred to the sample (see Table 2). In this part, only small amounts of SW gases were released, while noble gases residing in the grain volumes, such as the cosmogenic gases, were more prominent (Figs. 1, 2, and 5). Steps 11-20 released $\sim 40 \%$ of the primarily cosmogenic isotopes ${ }^{3} \mathrm{He}$ and ${ }^{21} \mathrm{Ne}$ in the whole etch run, corresponding to $\sim 35 \%$ of the concentration of these isotopes released in bulk pyrolysis. Lower relative amounts of ${ }^{4} \mathrm{He}$ and ${ }^{20} \mathrm{Ne}$ were released, about $10 \%$ of the total released in the etch run and $\sim 5 \%$ of the gases released in bulk pyrolysis. About $30-45 \%$ of the ${ }^{36} \mathrm{Ar},{ }^{84} \mathrm{Kr}$, and ${ }^{132} \mathrm{Xe}$ in the etch run were released in steps $11-20$, only representing a few percent of the gas concentrations released in bulk pyrolysis.

The ${ }^{3} \mathrm{He} /{ }^{4} \mathrm{He}$ ratio is clearly higher than the SW value, and hence shows contributions from cosmogenic He, in contrast to parts 1 and 3, in which He is SW-like (Fig. 2). The higher relative contribution of cosmogenic gases is also manifested by a ${ }^{36} \mathrm{Ar} /{ }^{38} \mathrm{Ar}$ ratio below the SW value (Fig. 6). As noted already, the Ne in most steps is a mixture of cosmogenic and SW-like noble gases with the contributions of cosmogenic Ne relative to SW Ne being higher in steps 1120 than in steps 1-10 (Fig. 1). However, steps 12, 13, 16, and 18 do not follow this simple pattern but require the presence of a third component. About $50 \%$ of the total ${ }^{21} \mathrm{Ne}_{\cos }$ in the etch run (2.59 $\times 10^{-9} \mathrm{~cm}^{3} \mathrm{STP} / \mathrm{g}$ ) was released in part 2 , mostly in step 11 (Fig. 5b). The concentration of cosmogenic Ne in Fig. 5 was estimated assuming the steps which fall on a mixing line between fSW and the cosmogenic component to be a mixture between the two. For steps 12, 13, 16, and 18 which plot away from the fSW-cos mixing line an additional component with a ${ }^{21} \mathrm{Ne} /{ }^{22} \mathrm{Ne}$ of 0.0294 and ${ }^{20} \mathrm{Ne} /{ }^{22} \mathrm{Ne}$ of 8.27 (the intercept of a line passing through steps 12,13 and the cosmogenic component with ${ }^{21} \mathrm{Ne} /{ }^{22} \mathrm{Ne}=0.0294$ ) was assumed. The presence of small amounts 
of the cosmogenic component is also visible in $\mathrm{Kr}$ and $\mathrm{Xe}$ (Fig. 7b, Table 3). Krypton showed enrichment in the isotope ${ }^{80} \mathrm{Kr}$ relative to the ${ }^{80} \mathrm{Kr} /{ }^{84} \mathrm{Kr}$ ratios of atmosphere, Q and, P3, indicating some cosmogenic $\mathrm{Kr}$ (Table 3). In major isotopic ratios the Xe isotopic pattern is in agreement with a mixture of $50 \%$ Q or P3 and $50 \%$ air based on ${ }^{132} \mathrm{Xe}$ (Fig. $7 \mathrm{~b}$ ). Excess of cosmogenic ${ }^{124,126} \mathrm{Xe}$ compared to a mixture of $50 \% \mathrm{Q}$ or P3 and $50 \%$ air based on ${ }^{132} \mathrm{Xe}$ is seen in Fig. 7. The excess of ${ }^{124} \mathrm{Xe}$ and ${ }^{126} \mathrm{Xe}$ is interpreted as cosmogenic $\mathrm{Xe}$ as the isotopic pattern is in good agreement with that of cosmogenic Xe (e.g., Hohenberg et al., 1981). The proportion of primordial Xe is higher relative to atmospheric Xe in part 2 than in part 1 . This is due to a combination of less atmospheric Xe and more trapped Xe being released from the sample in part 2 (Fig. 5). In addition to Q (or P3), air, and cosmogenic components, there is evidence for ${ }^{129} \mathrm{Xe}_{\text {rad }}$ and possibly also fission ${ }^{136} \mathrm{Xe}\left({ }^{136} \mathrm{Xe}_{\text {fiss }}\right)$. The highest ${ }^{129} \mathrm{Xe} /{ }^{132} \mathrm{Xe}$ ratio of the etch run is measured in step $14\left({ }^{129} \mathrm{Xe} /{ }^{132} \mathrm{Xe}=2.58\right.$, Fig. 8). However, most of the ${ }^{129} \mathrm{Xe}_{\text {rad }}$ is released in the gas-rich step 11, the same step that released most of the ${ }^{21} \mathrm{Ne}_{\cos }$ (Fig. 5b). Fission Xe is indicated by a somewhat higher ${ }^{136} \mathrm{Xe} /{ }^{132} \mathrm{Xe}$ ratio than expected from a mixture of $50 \% \mathrm{Q}$ or $\mathrm{P} 3$ and $50 \%$ air (Fig. 7b). As this deviation from the Q (or P3) - air mixture only affects the heavy Xe isotopes the elevated ${ }^{136} \mathrm{Xe} /{ }^{132} \mathrm{Xe}$ ratio is rather due to some addition of fission Xe than Xe-HL.

\subsubsection{Third part of the CSSE analysis (steps 21-27): primordial noble gases}

The last part of the etch run (steps 21-27) essentially started when the acid was fully transferred into the sample volume and temperatures were increased. Most of the volume-correlated gases had been released by the end of part 2 and other, minor, components became visible in part 3, especially in $\mathrm{Ne}$ (Fig. 1). Only $\sim 1 \%$ of ${ }^{3} \mathrm{He},{ }^{4} \mathrm{He}$, and ${ }^{21} \mathrm{Ne}$ in the etch run as a whole was released in part 3, and only $\sim 4 \%$ of ${ }^{20} \mathrm{Ne}$ and ${ }^{22} \mathrm{Ne}$ in the entire etch run was released in the last part, 
corresponding to $\sim 2 \%$ of the ${ }^{20} \mathrm{Ne}$ and ${ }^{22} \mathrm{Ne}$ released in bulk pyrolysis. The low fraction of light noble gases released in part 3 illustrates that these only represent minor components, both with respect to the gases released in the etch run and the gases in bulk pyrolysis. About $20-30 \%$ of ${ }^{36} \mathrm{Ar},{ }^{84} \mathrm{Kr}$, and ${ }^{132} \mathrm{Xe}$ in the whole etch run was released in part 3, corresponding to a few percent of the concentrations of these isotopes released in bulk pyrolysis.

There is no clear cosmogenic signature in any of the isotopic systems in part 3, showing that by the end of part 2 most of the volume-correlated cosmogenic noble gases had been released. Note that any sizeable cosmogenic signal present would not be over-printed by other components in the last part of the etch run, as only $\sim 1 \%$ of the ${ }^{3} \mathrm{He}$ and ${ }^{21} \mathrm{Ne}$ of the total etch run were released in part 3 . The scarcity of cosmogenic gas indicates that most of the sample had been etched away by the end of part 2 and that in part 3 we etched minor, particularly acidresistant phases. Argon, $\mathrm{Kr}$, and Xe were released in roughly similar amounts as in part $2(\sim 20-$ $30 \%$ of the total gas release in the etch run).

Remarkably, the He isotopic composition, which showed significant contributions of cosmogenic He in part 2, in part 3 is close to that of SW again (Fig. 2). Also cosmogenic ${ }^{21} \mathrm{Ne}$ is negligible in part 3 , with upper limits on the order of merely $10^{-13} \mathrm{~cm}^{3} \mathrm{STP} / \mathrm{g}$ in individual etch steps, assuming a primordial ${ }^{21} \mathrm{Ne} /{ }^{22} \mathrm{Ne}$ ratio of 0.0295 . In contrast to $\mathrm{He}, \mathrm{Ne}$ isotopes are not SW-like in the third part of the etch run. Fig. 1 shows that the Ne isotopes have a primordial composition, i.e., very low ${ }^{21} \mathrm{Ne} /{ }^{22} \mathrm{Ne}$ ratios, but lower ${ }^{20} \mathrm{Ne} /{ }^{22} \mathrm{Ne}$ ratios than $\mathrm{SW}$ or fSW.

The ${ }^{36} \mathrm{Ar} /{ }^{38} \mathrm{Ar}$ ratios in the steps of part 3 are in agreement with Q or air (Fig. 6). Most steps have ${ }^{40} \mathrm{Ar} /{ }^{36} \mathrm{Ar}$ ratios much lower than that of air, however, steps 24 and 25 have high ${ }^{40} \mathrm{Ar} /{ }^{36} \mathrm{Ar}$ ratios (Fig. 6) and the concentration of ${ }^{40} \mathrm{Ar}$ in step 24 is very high (Table 3). This indicates some atmospheric contamination, also supported by the position of the data points of 
steps 24 and 25 in a ${ }^{36} \mathrm{Ar} /{ }^{132} \mathrm{Xe}$ vs ${ }^{84} \mathrm{Kr} /{ }^{132} \mathrm{Xe}$ diagram. Atmospheric contamination was possibly the result of accidental bending of the sample container during the preparation of step 24 , presumably leading to release of atmospheric gases from the metal. It is difficult to correct for such contamination as the amount of elemental fractionation is unknown. These steps are not considered any further in the interpretation of all isotope and elemental ratios, they are also not shown in most figures.

The sum of the etch steps in part 3 has, similar to part 2, a Xe isotopic composition roughly in agreement with a mixture of $50 \%$ Q or P3 and $50 \%$ atmospheric Xe based on ${ }^{132} \mathrm{Xe}$ (Fig. 7). However, particularly ${ }^{124} \mathrm{Xe} /{ }^{132} \mathrm{Xe},{ }^{126} \mathrm{Xe} /{ }^{132} \mathrm{Xe}$, and also ${ }^{136} \mathrm{Xe} /{ }^{132} \mathrm{Xe}$ suggest addition of additional component(s). The Xe isotopic pattern in part 3 could be explained by an addition of up to $\sim 3 \% \mathrm{HL}$ in ${ }^{132} \mathrm{Xe}$. In contrast to part 2, there is no evidence for spallation Xe in part 3 (Fig. 7). Also no ${ }^{129} \mathrm{Xe}_{\text {rad }}$ is visible anymore in part 3 (Figs. 7 and 8). The lack of cosmogenic and radiogenic Xe shows that their carrier phases (phosphates and carbonates for cosmogenic Xe, Ibearing phases for radiogenic Xe) were essentially etched away in part 2.

\subsection{Bulk pyrolysis and how it compares with the CSSE analysis}

As a complement to the CSSE analysis, the single step pyrolysis of the bulk sample provides a full inventory of the noble gases in Ivuna, including those carried by refractory presolar grains and phase Q. This allows us to determine how much of the total gases and the gases related to specific components were released in the CSSE analysis. By and large, our bulk sample data compare quite well with literature values (Stauffer, 1961; Black and Pepin, 1969; Mazor et al., 1970; Black, 1972), although gas concentrations in our Ivuna sample are in general higher than the ones given in the literature by about a factor of 1.5 for ${ }^{20} \mathrm{Ne}$ and ${ }^{36} \mathrm{Ar}$, a factor of 2 for ${ }^{4} \mathrm{He}$, and a factor of 3 for ${ }^{132} \mathrm{Xe}$. Helium and $\mathrm{Ne}$ isotopic ratios in the sample analyzed here are within 
the range of the values given in the literature. Helium has an isotopic composition of ${ }^{3} \mathrm{He} /{ }^{4} \mathrm{He}=$ $(3.59 \pm 0.04) \times 10^{-4}$. Neon is dominated by primordial gases; cosmogenic Ne is clearly visible, too (Fig. 1). Although the total trapped Ne released during pyrolysis of the Ivuna bulk sample has $a^{20} \mathrm{Ne} /{ }^{22} \mathrm{Ne}$ ratio close to the atmospheric value of 9.8 , the CSSE data clearly exclude major contributions from atmospheric Ne. No individual CSSE etch step shows an atmospheric Ne signature. Rather, trapped Ne in individual steps is either dominated by SW or HL (section 3.1). The trapped Ne in the bulk sample is most likely dominated by HL with some addition of other components with higher ${ }^{20} \mathrm{Ne} /{ }^{22} \mathrm{Ne}$ ratios such as $\mathrm{Q}$ and $\mathrm{SW}$ (Fig. 1). The ${ }^{40} \mathrm{Ar} /{ }^{36} \mathrm{Ar}$ ratio is $3.47 \pm$ 0.02 , only slightly lower than the values reported by previous studies of 4.10-6.64 (Stauffer, 1961; Mazor et al., 1970). This ratio excludes the presence of any significant atmospheric Ar. The concentration of radiogenic ${ }^{40} \mathrm{Ar}\left((5.3 \pm 0.1) \times 10^{-6} \mathrm{~cm}^{3} \mathrm{STP} / \mathrm{g}\right)$ is similar to what was measured previously in Ivuna (Stauffer, 1961; Mazor et al., 1970) and Orgueil, another CI chondrite (Jeffery and Anders, 1970; Mazor et al., 1970). Krypton and Xe released during pyrolysis is dominated by the $\mathrm{Q}$ component (Fig. 7, Tables 3 and 4), which is also the case for the isotopic composition of Xe given by Mazor et al. (1970). Although roughly in agreement with Q, $\mathrm{Xe}$ has higher ${ }^{124} \mathrm{Xe} /{ }^{132} \mathrm{Xe}$ and ${ }^{136} \mathrm{Xe} /{ }^{132} \mathrm{Xe}$ ratios than pure $\mathrm{Q}$ (Fig. 7). This is often seen in primitive meteorites and attributed to the presence of Xe-HL. The data agree well with a mixture of $98.5 \% \mathrm{Q}$ and $1.5 \% \mathrm{HL}$ based on ${ }^{132} \mathrm{Xe}$, as can be seen in Fig. 7. A contribution of $\sim 2 \%$ HL to ${ }^{132} \mathrm{Xe}$ is also expected for a primitive meteorite like Ivuna (Ott, 2014).

The total concentration of ${ }^{3} \mathrm{He}$ and ${ }^{21} \mathrm{Ne}$ measured during the etch run corresponds to 75 $80 \%$ of the concentration of these gases released during pyrolysis of the bulk sample. These isotopes are mainly cosmogenic, produced by the spallation of major elements such as $\mathrm{O}, \mathrm{Si}$, and $\mathrm{Mg}$, which are predominantly situated in the phyllosilicates in Ivuna. The almost complete 
release of ${ }^{3} \mathrm{He}$ and ${ }^{21} \mathrm{Ne}$ in the etch run shows that most of the volume of the sample, i.e., the phyllosilicates, was etched away during the experiment. Lower relative amounts of ${ }^{20} \mathrm{Ne}$ and ${ }^{22} \mathrm{Ne}$ were released $(\sim 55 \%$ and $\sim 50 \%$ of the bulk concentrations, respectively) as these isotopes are carried to a large extent by acid-resistant presolar grains. This is also illustrated by the $\mathrm{Ne}$ isotopic composition. Figure 1 shows that the Ne isotopic composition of the sum of all steps in the etch run is in agreement with a mixture of fractionated SW (fSW) and cosmogenic Ne. The $\mathrm{Ne}$ isotopic composition of the gases released during pyrolysis of the bulk sample, on the other hand, is dominated by Ne-HL and cosmogenic Ne. Neon-HL is carried by acid-resistant presolar nanodiamonds, which are not significantly etched by HF. Neon-HL dominates the gases released during pyrolysis such that the comparably minor fSW-Ne, which is clearly seen in the etch run, is almost invisible in the pyrolysis bulk sample (Fig. 1). Similarly, the ${ }^{3} \mathrm{He} /{ }^{4} \mathrm{He}$ ratio of the sum of all etch steps is higher $\left({ }^{3} \mathrm{He} /{ }^{4} \mathrm{He}=(4.53 \pm 0.04) \times 10^{-4}\right)$ than in the gases released during pyrolysis of the bulk sample $\left({ }^{3} \mathrm{He} /{ }^{4} \mathrm{He}=(3.59 \pm 0.04) \times 10^{-4}\right)$, likely reflecting that presolar grains such as nanodiamonds with ${ }^{3} \mathrm{He} /{ }^{4} \mathrm{He}$ ratios $\leq 1.35 \times 10^{-4}$ (Huss and Lewis, 1994a) were not etched to a large extent in the CSSE analysis.

The total concentration of ${ }^{40} \mathrm{Ar}$ released in the etch run is 1.4 times that of the concentration of ${ }^{40} \mathrm{Ar}$ released during pyrolysis of the bulk sample. Heterogeneous distribution of ${ }^{40} \mathrm{Ar}$ in Ivuna is also evident from the literature (Stauffer, 1961; Mazor et al., 1970). Much less of the primordial heavy noble gases were released in the etch run, about $5 \%$ of the ${ }^{36} \mathrm{Ar}$ and $10-15 \%$ of the ${ }^{84} \mathrm{Kr}$ and ${ }^{132} \mathrm{Xe}$. This is expected since most of the heavy noble gases in meteorites are present in the HF-resistant phase Q. 


\subsection{Synthesis of the results}

The CSSE gas extraction technique allowed us to resolve noble gas components which were not obvious from the one step pyrolysis of the bulk sample, such as $\mathrm{SW} \mathrm{He}$ and Ne, cosmogenic $\mathrm{Kr}$ and $\mathrm{Xe}$, and radiogenic and fission Xe. Comparing the two data sets showed that most of the cosmogenic gases were released in the etch run, whereas Q-gases and gases residing in presolar grains were not released to any comparably large extent upon etching with HF. In the beginning of the etch run SW noble gases were released that had been implanted on the asteroid surface into the top nanometers of grains. As etching progressed, cosmogenic noble gases became more evident and cosmogenic isotope signatures were seen in all elements. Radiogenic isotopes were also released together with cosmogenic and SW noble gases. Cosmogenic and radiogenic noble gases are present in the bulk mineral grains and the release of these gases, therefore, shows that the bulk grains were largely dissolved in the middle part of the etch run. Primordial Xe, isotopically consistent with Q or P3, was released throughout the whole etch run. Air-Xe was mixed with the primordial $\mathrm{Xe}$; with a higher primordial/air ratio in the later etch steps than in the earlier ones. Primordial Ne was also observed, mainly in the last part of the etch run after most SW and cosmogenic noble gases had already been released, but also in some etch steps with smaller gas amounts earlier in the etch run.

\section{Discussion}

\subsection{Primordial noble gases in HF-solubles}

In this work we analyzed the noble gases in the HF-soluble fraction of a primitive meteorite, which would usually be dissolved prior to primordial noble gas studies. As hypothesized in the introduction, these solubles indeed contain primordial noble gases. This is the first time that 
primordial noble gases have been demonstrated to be present in the HF-solubles of a CI chondrite and it shows that information about primordial noble gases are lost when exclusively investigating $\mathrm{HF} / \mathrm{HCl}-$ resistant residues.

\subsubsection{Isotopic composition and concentration of primordial $\mathrm{Ne}$}

The steps containing primordial Ne also contained other Ne components that must be disentangled before the primordial Ne can be discussed further. Steps 12, 13, 16, 18, 21-23, and 26-27 contain primordial $\mathrm{Ne}$, based on a ${ }^{20} \mathrm{Ne} /{ }^{22} \mathrm{Ne}$ ratio of the trapped component below the fractionated solar wind value (Fig. 1). Based on the SW-like composition of He in steps 21-23 and 26-27 and a He composition in agreement with a mixture between SW and cosmogenic gases in steps $12,13,16$, and 18 , we expect some Ne-SW to be admixed to the primordial Ne. This was corrected for based on the concentration of He-SW in these steps (electronic Annex). For steps $12,13,16$, and 18 the ${ }^{20} \mathrm{Ne} /{ }^{22} \mathrm{Ne}$ ratio was also corrected for cosmogenic $\mathrm{Ne}$ (electronic Annex).

The resulting ${ }^{20} \mathrm{Ne} /{ }^{22} \mathrm{Ne}$ ratio of the primordial Ne component is $8.40 \pm 0.11$. The ${ }^{20} \mathrm{Ne}$ concentration of the primordial Ne component released in the CSSE run of Ivuna is $\sim 9.5 \times 10^{-9}$ $\mathrm{cm}^{3} \mathrm{STP} / \mathrm{g}$. This figure should be seen as a lower limit as parts of this component might have been released in etch steps rich in cosmogenic and SW Ne and, hence, overlooked. In addition, some trapped Ne was likely present in the air-contaminated steps 24 and 25 which were not included in the calculation.

\subsubsection{Relation to known primordial noble gas components and their carriers}

The HF-soluble portion of Ivuna contains primordial Ne and Xe with isotopic and elemental compositions in good agreement with the two most widespread components HL and Q. The 
${ }^{20} \mathrm{Ne} /{ }^{22} \mathrm{Ne}$ ratio of the primordial $\mathrm{Ne}$ in the solubles of $8.40 \pm 0.11$ is identical to the ${ }^{20} \mathrm{Ne} /{ }^{22} \mathrm{Ne}$ ratio of HL of $8.500 \pm 0.057$ (Huss and Lewis, 1994a). The Xe isotopic composition is very similar to Q (or P3), with hints of small amounts of Xe-HL in part 3 of the etch run (Fig. 7c). In addition to HL, nanodiamond separates contain another exotic Xe component, Xe-P6, with an isotopic composition very similar to Xe-HL (Gilmour et al., 2005). We cannot separate between the two in our data set, and they have also been suggested to be variations of the same component (Gilmour et al., 2005). Because Xe-HL is more prominent than Xe-P6 in nanodiamond separates, the exotic Xe is here referred to as HL. The average Q component as measured in several chondrites has a ${ }^{20} \mathrm{Ne} /{ }^{132} \mathrm{Xe}$ ratio of $3.2 \pm 0.5$ (Busemann et al., 2000). Adopting this ratio and the concentration of ${ }^{132} \mathrm{Xe}_{\mathrm{Q}}$ in the HF-solubles, the expected concentration of ${ }^{20} \mathrm{Ne}_{\mathrm{Q}}$ in the HFsolubles of Ivuna is $\sim 9.9 \times 10^{-10} \mathrm{~cm}^{3} \mathrm{STP} / \mathrm{g}$ (electronic Annex 1). The remaining primordial gases, after subtraction of Xe-Q and Ne-Q, are similar to $\mathrm{HL} ;{ }^{20} \mathrm{Ne} /{ }^{22} \mathrm{Ne}=8.21 \pm 0.20$ (c.f. $\mathrm{HL}=$ $8.500 \pm 0.057$; Huss and Lewis, $1994 \mathrm{a}) ;{ }^{20} \mathrm{Ne} /{ }^{132} \mathrm{Xe} \sim 453$ (c.f. HL $=485 \pm 26$; Huss and Lewis, 1994b; Ott, 2014). Generally, the Q component is carried by phase Q and the HL-gases are known to be carried by nanodiamonds. Phase Q is the main carrier of primordial heavy noble gases in CI chondrites whereas HL is the most abundant component of the light noble gases in such samples (e.g., Ott, 2014). HL-like Ne in the solubles only account for $\sim 3 \%$ of the total NeHL released during pyrolysis of the bulk sample. Similarly, $\sim 4 \%$ of the ${ }^{132} \mathrm{Xe}_{\mathrm{Q}}$ released from Ivuna during pyrolysis was released during etching with HF.

It is plausible that Q-gases were released from phase Q proper. Phase Q is operationally defined as surviving treatment with $\mathrm{HF}$ and $\mathrm{HCl}$, but releasing the Q-gases when treated with an oxidizing agent such as $\mathrm{HNO}_{3}$ (Lewis et al., 1975). However, it has been known for a long time that some of the Q-gases are lost when preparing HF/HCl-resistant residues. Huss et al. (1996) typically lost some $10-25 \%{ }^{132} \mathrm{Xe}_{\mathrm{Q}}$ during residue preparation. We, therefore, consider it possible 
that the $\sim 4 \%$ of ${ }^{132} \mathrm{Xe}_{\mathrm{Q}}$ released upon $\mathrm{HF}$-etching resided in phase Q proper. Some $20-55 \%$ of the carbon in meteorites of many different classes cannot be accounted for by insoluble organic matter (IOM; effectively identical to the $\mathrm{HF} / \mathrm{HCl}$-resistant residues that carry most of the primordial noble gases), carbonates, and soluble organic matter (SOM; Alexander et al., 2015). This so called missing carbon could either be very fine-grained IOM that is lost during IOM preparation or carbonaceous matter with acid hydrolysable functional groups on IOM (Alexander et al., 2015). The missing carbon could perhaps be the carrier of HF-soluble Q.

The presence of HL-like Ne and Xe in the HF-solubles is more difficult to explain with gas-release from presolar nanodiamonds during CSSE analysis. The HL-gases released in the etch run only represent a minor fraction of $\sim 3 \%$ of the concentration of HL released during pyrolysis of the bulk sample. Yet, the absolute concentration of ${ }^{20} \mathrm{Ne}_{\mathrm{HL}}$ in HF-soluble phases of $\sim 9.5 \times 10^{-9} \mathrm{~cm}^{3} \mathrm{STP} / \mathrm{g}$ is far from negligible. Nanodiamond separates are very resistant to chemical etching and preparation of nanodiamond separates includes extensive treatment with various acids, including HF (Lewis et al., 1987; Huss and Lewis, 1994a). The HL-gases are released from nanodiamond separates at relatively high temperatures during stepwise heating, indicating that these gases are tightly bound to the carriers (Huss and Lewis, 1994a). The P3gases are released at lower temperatures, indicating that they are less tightly bound, likely on the surfaces of the carriers (Huss and Lewis, 1994a). It, therefore, seems unlikely that HL would be released from nanodiamonds when treated with HF without accompanying P3-gases. We cannot fully exclude that Xe-P3 was present in the HF-solubles instead of Xe-Q, but we prefer the simpler alternative that the primordial gases are a combination of Q and HL-like gases. If the Qlike gases were P3 gases instead, then we would expect to have approximately twice as much $\mathrm{Ne}$ as measured, as $\mathrm{P} 3$ has a higher ${ }^{20} \mathrm{Ne} /{ }^{132} \mathrm{Xe}$ ratio than $\mathrm{Q}$, and we would expect a small addition of $\mathrm{Ne}-\mathrm{E}$, as P3 has a higher ${ }^{20} \mathrm{Ne} /{ }^{22} \mathrm{Ne}$ of $\sim 8.9$ than the one of $\sim 8.5$ for HL. 
The HL-like primordial noble gas component in the HF-solubles differs from HL in nanodiamond separates in that it does not contain any He-HL. The primordial component has a ${ }^{4} \mathrm{He} /{ }^{20} \mathrm{Ne}$ ratio of $\sim 100$ (Fig. 4), much lower than the value of $\sim 600$ characteristic for the HL component carried by presolar nanodiamonds (Huss and Lewis, 1994b; Lewis et al., 1994; Ott, 2014). In addition, the ${ }^{3} \mathrm{He} /{ }^{4} \mathrm{He}$ ratio in the etch steps in part 3 is not in agreement with $\mathrm{HL}$, but rather with SW and the He isotopic composition in steps $12,13,16$, and 18 is in agreement with a mixture of SW and cosmogenic He (Fig. 2). The lack of HL-He is perhaps most easily understood as loss of He from the HF-soluble carrier of HL.

Potential carrier phases of HL are presolar grain types which have previously not been shown to carry primordial noble gases. If these are identified to carry noble gases then the noble gases would provide additional tools to test nucleosynthetic models. Apart from the already discussed C-rich presolar grains known to carry noble gases, two major types of presolar grains are known to be present in meteorites: silicates and oxides (e.g., Zinner, 2014). It is unlikely that the primordial noble gases were released from presolar silicates, as primordial noble gases were most prominent in part 3 of the CSSE analysis when all the phyllosilicates and presumably also any presolar silicates had already been etched away (see section 3.3.3). Presolar oxides are more promising candidates. Most presolar oxides (corundum, spinel, hibonite; Zinner, 2014) are largely resistant to $\mathrm{HF}$, similar to presolar nanodiamonds, $\mathrm{SiC}$, and graphite. However, the surfaces of presolar $\mathrm{SiC}$ grains separated using conventional acid separation schemes have etch pits, showing that these grains are not completely resistant to acid treatment (see Fig. 6 in Bernatowicz et al., 2003). In view of this, we consider it plausible that also presolar oxides could be partially attacked by HF during severe etching in the late etch steps. To our knowledge, the only attempt to search for primordial noble gases in oxide grains was done on $\mathrm{HF} / \mathrm{HCl}$ separates 
from Allende (CV3; Lewis and Srinivasan, 1993). These separates were diluted with far more abundant oxides formed in the Solar System and did not show any evidence for primordial noble gases. In an oxygen ion imaging search for presolar oxides in a residue from Tieschitz (H/L) only $\sim 4 \%$ of the grains were found to be presolar (Nittler et al., 1994). Most presolar oxides are, based on their oxygen isotopic composition, from oxygen-rich, low mass red giant branch and asymptotic giant branch (AGB) stars (Nittler et al., 1997). Such stars are not expected to produce $\mathrm{Xe}-\mathrm{HL}$, enriched in both p-process nuclides $\left({ }^{124} \mathrm{Xe}\right.$ and $\left.{ }^{126} \mathrm{Xe}\right)$ and r-process nuclides $\left({ }^{134} \mathrm{Xe}\right.$ and $\left.{ }^{136} \mathrm{Xe}\right)$. However, some presolar oxide grains have been shown to have a supernovae origin (Nittler et al., 1998; Gyngard et al., 2010). If grains which carry other isotopic evidence for supernova origin also carry Xe-HL, then this would be a confirmation that also Xe-HL is of supernovae origin (c.f., Ott, 1996). We can estimate the hypothetical concentration of primordial ${ }^{20} \mathrm{Ne}$ in presolar oxide grains by adopting the concentration of O-rich presolar grains in finegrained chondrule rims of CM chondrites of $\sim 14$ ppm (Leitner et al., 2016) as the concentration of presolar oxide grains in bulk Ivuna. This hypothetical concentration of presolar oxide grains gives a resonable ${ }^{20} \mathrm{Ne}$ concentration in these grains of $\sim 6 \times 10^{-4} \mathrm{~cm}^{3} \mathrm{STP} / \mathrm{g}$.

Another possible HF-susceptible carrier of primordial HL-like noble gases in Ivuna is presolar $\mathrm{Si}_{3} \mathrm{~N}_{4}$. HF is used to etch $\mathrm{Si}_{3} \mathrm{~N}_{4}$ in material science applications (Knotter and Denteneer, 2001), indicating that presolar $\mathrm{Si}_{3} \mathrm{~N}_{4}$ grains most likely also are partially HF-soluble when etched for long times and at elevated temperatures. Also, Nittler and Alexander (2003) reported hints that $\mathrm{HF}$ treatment leads to destruction of some presolar $\mathrm{Si}_{3} \mathrm{~N}_{4}$ grains. Presolar $\mathrm{Si}_{3} \mathrm{~N}_{4}$ grains are mainly of supernovae origin, with isotopic compositions similar to $\mathrm{SiC} \mathrm{X}$-grains (e.g., Lin et al., 2002; Zinner et al., 2007). Although, it is possible that some $\mathrm{Si}_{3} \mathrm{~N}_{4}$ grains formed in AGB stars (Zinner et al., 2007). Some primordial noble gases could perhaps have been released from $\mathrm{Si}_{3} \mathrm{~N}_{4}$ 
grains during etching, however, it is extremely unlikely that all primordial HL-like gases released from Ivuna during $\mathrm{HF}$ treatment were resided in $\mathrm{Si}_{3} \mathrm{~N}_{4}$. Adopting a concentration of $\mathrm{Si}_{3} \mathrm{~N}_{4}$ grains of $2 \mathrm{ppb}$ as previously determined for Murchison (CM2; Nittler et al, 1995), the resulting concentration of ${ }^{20} \mathrm{Ne}$ in these grains would be $\sim 4 \mathrm{~cm}^{3} \mathrm{STP} / \mathrm{g}$, several orders of magnitude higher than typical concentrations of $\mathrm{Ne}$ in presolar grains.

Gilmour (2010) proposed that Q-Xe is a mixture of mass-fractionated solar Xe and HL$\mathrm{Xe}$ (plus some radiogenic ${ }^{129} \mathrm{Xe}$ ). This model was revisited by Crowther and Gilmour (2013) and Gilmour et al. (2016). Meshik et al. (2014) proposed a similar model but with small amounts of Xe-S (a Xe component synthesized during the stellar s-process nucleosynthesis) added to fractionated solar Xe in addition to Xe-HL. Our data could be explained similarly: Xe in the HFsolubles would be solar Xe, mass fractionated to the same extent as classical Q-Xe, to which a somewhat higher proportion of Xe-HL was admixed than to the classical Q-Xe. The Xe-S fraction of Xe-Q suggested by Meshik et al. (2014) is small (Xe-HL/Xe-S 16) and would not be detectable if present in the current dataset. Although this is an appealing model for Xe in the HFsoluble portion of Ivuna, it does not explain the primordial $\mathrm{Ne}$ as the primordial $\mathrm{Ne}$ in the HFsolubles has an isotopic composition close to HL and distinct from Ne-Q and the model for Qgases by Gilmour (2010), Crowther and Gilmour (2013), Meshik et al. (2014), and Gilmour et al. (2016) does not consider Ne. There is also no obvious explanation for why HF-soluble Q should contain more HL than the canonical Q component, but note that the average Xe-HL in in Q of $\sim 1.5 \%$ in the model varies significantly between $\sim 0.2 \%$ and $\sim 3.3 \%$ for different samples (Crowther and Gilmour, 2013). 


\subsection{Solar wind}

The release pattern of SW-like noble gases in part 1 of the etch run (steps 1-10) is consistent with $\mathrm{SW}$ acquired in a regolith breccia. The SW-like $\mathrm{He}$ and $\mathrm{Ne}$ is released early, as has previously been observed in many etch runs on samples from the lunar and asteroidal regoliths, which contain implanted SW (e.g., Benkert et al., 1993; Murer et al., 1997). The early release of SW noble gases, therefore, shows that Ivuna is a regolith breccia. This is not surprising; it is fragmented (e.g., Morlok et al., 2006) and previous bulk measurements also indicate the presence of solar noble gases (Stauffer, 1961; Black and Pepin, 1969; Mazor et al., 1970; Black, 1972). In addition, magnetite separates from Orgueil (CI) have been shown to contain SW gases (Jeffery and Anders, 1970), and many CM chondrites contain SW noble gases (e.g., Nakamura et al., 1999).

Some of the etch steps contained SW with an unfractionated elemental composition (Fig. 4). Unfractionated SW has been observed previously in metal from different meteorites; metal is more retentive to light noble gases than silicates (Pedroni and Begemann, 1994; Murer et al., 1997). However, unfractionated SW has previously only been observed in silicate fractions from one H chondrite, Acfer 111 (Pedroni and Begemann, 1994). CI chondrites like Ivuna do not contain metal (Krot et al., 2014) so the elementally unfractionated SW in steps 6-10 in this study cannot be explained by etching of metal, but must be retained in some other phase.

The first 5 etch steps had lower than solar ${ }^{4} \mathrm{He} /{ }^{20} \mathrm{Ne}$ ratios (Figs. 3 and 4) Similar trends have previously been observed in etch experiments with lunar samples and the $\mathrm{H}$ chondrite Noblesville and were explained by diffusive loss of $\mathrm{He}$ from the outermost parts of the grains (Murer et al., 1997; Heber et al., 2003). This explanation could also be valid for Ivuna. Alternatively, or in addition, the increase in ${ }^{4} \mathrm{He} /{ }^{20} \mathrm{Ne}$ ratios over the etch run could be explained 
by minerals more retentive for ${ }^{4} \mathrm{He}$ being etched later than minerals less retentive for ${ }^{4} \mathrm{He}$. One such retentive mineral could be magnetite which makes up $\sim 5 \mathrm{vol} \%$ of CI chondrites (Bland et al., 2004). Jeffery and Anders (1970) analyzed different separates of Orgueil (CI) and observed a stronger SW signature in the magnetite separate than in the silicate separate. Although the authors at the time interpreted the data to indicate pre-accretionary SW, the strong SW signal in the magnetite separate is likely due to a stronger SW retentivity of magnetite compared to silicates. Summing up steps 1-10 gives a more usual fractionated SW (fSW) value for the ${ }^{4} \mathrm{He} /{ }^{20} \mathrm{Ne}$ ratio of 455 (c.f., e.g., Heber et al., 2003).

Another interesting observation is that the He isotopic ratios are close to the SW value in all steps of the third part of the etch run. Previous CSSE analyses have revealed that E and CV chondrites contain a component with elemental ratios similar to the SW (Christen and Busemann, 2004; Busemann et al., 2003a,b). Due to properties of this solar-like component, such as the release pattern, it was interpreted as being a primordial, pre-accretionary component and not implanted by the SW in a regolith. Such a primordial solar component could either have been implanted into the accreting material by early SW, or could have been incorporated into the accreting material from the solar nebula (Busemann et al., 2003b, 2006). It is an intriguing thought that the He isotopic composition in part three of the etch run also is indicative of preaccretionary solar gases. The most straightforward explanation for the solar-like He in part 3 of the etch run is, however, that it is regolith-derived SW from the surfaces of relatively HFresistant phases, or from grain boundaries that had not yet been exposed to the acid. Most of the SW was released in part 1, most likely from the surfaces of the most common minerals in Ivuna such as phyllosilicates. A few percent of the total SW was also released in part 2 of the etch run (Fig. 5), as clearly seen in the Ne isotopes (Fig. 1). It appears likely that this minor release of SW continued also in part 3 of the etch run, with the decrease in release of SW representing that less 
surface material was available and that more resistant phases were etched. Neon-SW is not directly visible from the Ne three isotope plot in part 3 of the etch run. However, as seen in section 4.1.1 and in the electronic annex, it is expected that only $\sim 20 \%$ of the measured ${ }^{20} \mathrm{Ne}$ in part 3 of the etch run is SW, based on the concentration of ${ }^{4} \mathrm{He}$ SW. Neon-SW is, therefore, expected to be hidden among the more abundant primordial Ne in part 3 of the etch run.

\subsection{Cosmogenic noble gases}

Cosmogenic noble gases were observed in part 1 and part 2 of the etch run; all elements showed cosmogenic isotope signatures. The cosmogenic signal was most prominent in part 2 of the etch run. Excess of cosmogenic ${ }^{124} \mathrm{Xe}$ and ${ }^{126} \mathrm{Xe}$ relative to a background mixture of $\mathrm{Q}$ and air in part 2 is seen in Fig. 7. The concentration of ${ }^{126} \mathrm{Xe}_{\mathrm{cos}}\left(\sim 7 \%\right.$ of $\left.{ }^{126} \mathrm{Xe}_{\text {meas }}\right)$ is much higher than expected based on the concentration of ${ }^{21} \mathrm{Ne}_{\cos }\left(\sim 0.2 \%\right.$ of $\left.{ }^{126} \mathrm{Xe}_{\text {meas }}\right)$ and using production rate ratios from Eugster (1988). This indicates inhomogeneous distribution of the target elements for cosmogenic $\mathrm{Xe}(\mathrm{REE}, \mathrm{Ba})$ relative to those for cosmogenic $\mathrm{Ne}(\mathrm{Mg}, \mathrm{Al}, \mathrm{Si})$. Target elements for cosmogenic $\mathrm{Ne}$ are mainly present in the phyllosilicates, whereas target elements for cosmogenic Xe are expected to mainly be present in minor phases, such as phosphates and, to some extent, carbonates. Phosphates have a very heterogeneous distribution in CI chondrites (Morlok et al., 2006). Based on the concentration of cosmogenic Xe in part 2 of the etch run, REE concentrations in phosphate fragments in CI chondrites (Morlok et al., 2006) and Ba in phosphates of stony meteorites (Mason and Graham, 1970), we estimate 20 vol\% of our Ivuna sample to be phosphate. For illustrative purposes we can envision that all the cosmogenic Xe released in our etch run came from one single phosphate fragment. Such a fragment would be $\sim 2$ times larger than the 500-600- micron sized one illustrated by Morlok et al. 2006. This comparison shows that the amount of phosphate deduced from the observed cosmogenic Xe is 
reasonable, although multiple smaller phosphate fragments might be conceivable. Cosmogenic Xe is not seen in part 1 or part 3, indicating that the phosphates were etched exclusively in part 2.

Also the $\mathrm{Kr}$ in part 2 contains cosmogenic isotopes, visible in the ${ }^{80} \mathrm{Kr} /{ }^{84} \mathrm{Kr}$ ratio. In contrast to what was seen in Xe, this excess is roughly in agreement with what is expected from ${ }^{21} \mathrm{Ne}_{\mathrm{cos}}$ concentration and production rate ratios (Eugster, 1988). The main target elements for cosmogenic $\mathrm{Kr}$ are $\mathrm{Rb}, \mathrm{Sr}, \mathrm{Y}$, and $\mathrm{Zr}$, which are mainly expected to be in carbonates and phyllosilicates in CI chondrites, the main host minerals also for the target elements of ${ }^{21} \mathrm{Ne}_{\mathrm{cos}}$. Slightly elevated ${ }^{80} \mathrm{Kr} /{ }^{84} \mathrm{Kr}$ ratios compared to air, Q and, P3 are also seen in part 1, but not in part 3 of the etch run, consistent with ${ }^{21} \mathrm{Ne}_{\cos }$ which is released in part 1 and 2, but not in part 3 (Fig. 5). Both the cosmogenic ${ }^{21} \mathrm{Ne}$ and ${ }^{80} \mathrm{Kr}$ hence agree with most of the bulk material having been etched away in parts 1 and 2 of the etch run.

\subsection{Radiogenic and fissiogenic noble gases}

Radiogenic noble gases were observed in part 1 and 2 of the etch run. As for the cosmogenic noble gases, this is in line with most of the bulk material of the sample having been etched in the first and second part of the etch run. Argon-40 from decay of ${ }^{40} \mathrm{~K}$ was observed as well as ${ }^{129} \mathrm{Xe}$ from decay of ${ }^{129} \mathrm{I}$ (Fig. 5). In part 2 there was also some evidence of Xe from fission of ${ }^{244} \mathrm{Pu}$ and ${ }^{238} \mathrm{U}$.

Argon-40 in the CSSE analysis is somewhat compromised by atmospheric contamination. The concentration of ${ }^{40} \mathrm{Ar}$ released during pyrolysis of the bulk sample can be used to determine an Ar retention age, this gives a $\sim 1.6 \mathrm{Ga}$ nominal ${ }^{40} \mathrm{Ar}$ age, assuming an average CI chondrite concentration of K of 550 ppm (Lodders and Fegley, 1998). The reason for this relatively low KAr age is unclear. However, K-Ar ages for carbonaceous chondrites are generally difficult to 
determine and minerals in carbonaceous chondrites probably have a low retentivity for Ar, and small grain sizes might lead to recoil loss (Eugster et al., 1998; Turrin et al., 2014). Recent studies found Ar/Ar ages of several sub-samples of Murchison (CM2) between 2.0-3.2 Ga (Delaney et al., 2016; Turrin et al., 2014).

In part two of the etch run there was some evidence for fission Xe, manifested by an elevated ${ }^{136} \mathrm{Xe} /{ }^{132} \mathrm{Xe}$ ratio relative to a mixture of $50 \% \mathrm{Q}$ and $50 \%$ air as indicated by other $\mathrm{Xe}$ isotopic ratios. The small excess in ${ }^{136} \mathrm{Xe}$ does not allow determination of whether the potential fission $\mathrm{Xe}$ is dominated by fission of ${ }^{244} \mathrm{Pu}$ or ${ }^{238} \mathrm{U}$. When assuming the trapped $\mathrm{Xe}$ to be $50 \% \mathrm{Q}$ and $50 \%$ air the excess ${ }^{136} \mathrm{Xe}$ is $\sim 4.7 \times 10^{-12} \mathrm{~cm}^{3} \mathrm{STP} / \mathrm{g}$. This is higher than the total amount of fission Xe of $\sim 5 \times 10^{-13} \mathrm{~cm}^{3} \mathrm{STP} / \mathrm{g}$ expected from bulk Ivuna based on (i) a U concentration of $0.00749 \mu \mathrm{g} / \mathrm{g}$ and the product of decay constant and fractional yield of ${ }^{136} \mathrm{Xe}$ of $6.83 \times 10^{-18} \mathrm{a}^{-1}$ (Ragettli et al., 1994) for ${ }^{238} \mathrm{U}$, and (ii) a Nd concentration of $0.479 \mu \mathrm{g} / \mathrm{g}$ (Barrat et al., 2012), a ${ }^{244} \mathrm{Pu} /{ }^{150} \mathrm{Nd}$ atomic ratio of $1.6 \times 10^{-3}$ (Lugmair and Marti, 1977), and a ${ }^{136} \mathrm{Xe}$ fission yield of $7 \times$ $10^{-5}$ for ${ }^{244} \mathrm{Pu}$ (Hilton and Porcelli, 2014). However, the high abundance of fission Xe agrees nicely with the considerable abundance of phosphates in our sample ( $20 \mathrm{vol} \%)$, inferred from the abundance of cosmogenic Xe (section 4.3), as $\mathrm{Nd}$ and $\mathrm{U}$ are concentrated in phosphates. Phosphate fragments in CI chondrites have an average Nd concentration of $30.9 \mu \mathrm{g} / \mathrm{g}$ (Morlok et al., 2006), compared to $0.479 \mu \mathrm{g} / \mathrm{g}$ in bulk Ivuna (Barrat et al., 2012). Using these values, the expected concentration of ${ }^{136} \mathrm{Xe}_{\text {fiss }}$ in our phosphate-rich sample of Ivuna is $\sim 6.8 \times 10^{-12}$ $\mathrm{cm}^{3} \mathrm{STP} / \mathrm{g}$, in the same order as the ${ }^{136} \mathrm{Xe}$ excess in part 2 of $\sim 4.7 \times 10^{-12} \mathrm{~cm}^{3} \mathrm{STP} / \mathrm{g}$. We, therefore, conclude that ${ }^{136} \mathrm{Xe}_{\text {fiss }}$ likely is present in part 2 of the etch run in a concentration in agreement with what is expected for our phosphate-rich piece of Ivuna. 


\section{Summary}

In this study we report for the first time direct measurements of primordial noble gases in HFsoluble phases in a $\mathrm{CI}$ chondrite. Primordial noble gases were present in $\mathrm{Ne}$ and $\mathrm{Xe}$, but not detectable in the other noble gases. The isotopic and elemental compositions of the primordial Ne and Xe agree well with those calculated for a mixture containing two of the most common primordial noble gas components in primitive meteorites, HL and Q. Argon-Q and $\mathrm{Kr}-\mathrm{Q}$ are likely present in the data, but not possible to distinguish from isotopically very similar atmospheric noble gases. The carrier(s) of the primordial gases released during etching with HF is/are unknown. The primordial noble gases could have been released from their known respective carriers: phase $\mathrm{Q}$ and presolar nanodiamonds. Whereas it seems likely that Q-gases were released from phase Q proper during CSSE analysis with HF, it is more difficult to explain the presence of HL; nanodiamonds are HF-resistant minerals and if HL was released from the nanodiamonds during etching with HF, we would expect to also see the less tightly bound P3gases typically detected in nanodiamonds. Another puzzling fact is that there is no evidence for He-HL accompanying Ne-HL in the CSSE steps. Helium-HL is, similarly to Ne-HL, abundant in nanodiamonds.

Early release of He-SW and Ne-SW in the CSSE analysis confirms that Ivuna is a regolith breccia. Surprisingly, in some etch steps the ${ }^{4} \mathrm{He} /{ }^{20} \mathrm{Ne}$ ratio is in agreement with unfractionated SW. Elementally unfractionated SW has, to our knowledge, only been observed in the silicate fraction of one other meteorite, Acfer 111 (Pedroni and Begemann, 1994). The He isotopic composition is in agreement with SW not only in the early etch steps, but also in the last part of the etch run. We interpret also this late release of He-SW during harsh etching as regolith-derived 
SW; released from more HF-resistant phases than SW seen in the early etch steps, or, from phases protected from etching in the earlier steps by adhering material.

In addition to primordial $\mathrm{Ne}$ and $\mathrm{Xe}$ and $\mathrm{SW}$ noble gases, the etch run released cosmogenic gases in all elements, including $\mathrm{Kr}$ and $\mathrm{Xe}$. The concentration of cosmogenic Xe is surprisingly high compared to the concentration of cosmogenic Ne, indicating that our sample of Ivuna was rich in $\mathrm{Ba}$ and REE-bearing minerals, such as phosphates, also confirmed by a high

concentration of fission Xe. Radiogenic ${ }^{129} \mathrm{Xe}$ and ${ }^{40} \mathrm{Ar}$ were also detected in the etch run.

\section{Acknowledgments}

This work was supported by the Swiss National Science Foundation, grant numbers 200020_143950 and 200020_126460. The manuscript was significantly improved thanks to detailed reviews by an anonymous reviewer, Jamie D. Gilmour, and Alex Meshik, as well as by comments from associate editor Gregory F. Herzog. 


\section{References}

Alaerts L., Lewis R.S. and Anders E. (1979a) Isotopic anomalies of noble-gases in meteorites and their origins. 3. LL-chondrites. Geochim. Cosmochim. Acta 43, 1399-1415.

Alaerts L., Lewis R.S. and Anders E. (1979b) Isotopic anomalies of noble-gases in meteorites and their origins. 4. C-3 (Ornans) carbonaceous chondrites. Geochim. Cosmochim. Acta 43, 1421-1432.

Aléon J., Robert F., Duprat J., and Derenne S. (2005) Extreme oxygen isotope ratios in the early Solar System. Nature 437, 385-388.

Alexander C.M.O'D., Bowden R., Fogel M. L., and Howard K. T. (2015) Carbonate abundances and isotopic compositions in chondrites. Meteorit. Planet. Sci. 50, 810-833.

Amari S., Anders E., Virag A. and Zinner E. (1990) Interstellar graphite in meteorites. Nature 345, 238240.

Amari S., Lewis R.S. and Anders E. (1994) Interstellar grains in meteorites. 1. Isolation of SiC, graphite and diamond - size distributions of $\mathrm{SiC}$ and graphite. Geochim. Cosmochim. Acta 58, 459-470.

Barrat J.A., Zanda B., Moynier F., Bollinger C., Liorzou C. and Bayon G. (2012) Geochemistry of CI chondrites: Major and trace elements, and $\mathrm{Cu}$ and $\mathrm{Zn}$ Isotopes. Geochim. Cosmochim. Acta 83, 79-92.

Becker R.H., Schlutter D.J., Rider P.E. and Pepin R.O. (1998) An acid-etch study of the Kapoeta achondrite: Implications for the argon-36/argon-38 ratio in the solar wind. Meteorit. Planet. Sci. 33, 109-113.

Benkert J.-P. (1989) Solare Edelgase bei stufenweisem Aetzen von Iimeniten und Pyroxenen aus dem Mondregolith. Ph. D. thesis, ETH Zurich.

Benkert J.-P., Baur H., Signer P. and Wieler R. (1993) He, Ne, and Ar from the solar-wind and solar energetic particles in lunar ilmenites and pyroxenes. Journal of Geophysical Research-Planets $\mathbf{9 8 ,}$ 13147-13162.

Bernatowicz T., Fraundorf G., Tang M., Anders E., Wopenka B., Zinner E. and Fraundorf P. (1987) Evidence for interstellar SiC in the Murray carbonaceous meteorite. Nature 330, 728-730.

Bernatowicz T.J., Messenger S., Pravdivtseva O., Swan P. and Walker R.M. (2003) Pristine presolar silicon carbide. Geochim. Cosmochim. Acta 67, 4679-4691.

Black D.C. (1972) Origins of trapped helium, neon and argon isotopic variations in meteorites. 2. Carbonaceous meteorites. Geochim. Cosmochim. Acta 36, 377-394.

Black D.C. and Pepin R.O. (1969) Trapped neon in meteorites - II. Earth Planet. Sci. Lett. 6, 395-405.

Bland P.A., Cressey G. and Menzies O.N. (2004) Modal mineralogy of carbonaceous chondrites by X-ray diffraction and Mossbauer spectroscopy. Meteorit. Planet. Sci. 39, 3-16.

Busemann H., Baur H. and Wieler R. (2000) Primordial noble gases in "phase Q" in carbonaceous and ordinary chondrites studied by closed-system stepped etching. Meteorit. Planet. Sci. 35, 949-973.

Busemann H., Eugster O., Baur H. and Wieler R. (2003a) The ingredients of the "subsolar" noble gas component. Lunar Planet. Sci. XXXIV, \#1674 (abstr.).

Busemann H., Baur H. and Wieler R. (2003b) Solar noble gases in enstatite chondrites and implications for the formation of the terrestrial planets. Lunar Planet. Sci. XXXIV, \#1665 (abstr.).

Busemann H., Lorenzetti S. and Eugster O. (2006) Noble gases in D'Orbigny, Sahara 99555 and D'Orbigny glass - Evidence for early planetary processing on the angrite parent body. Geochim. Cosmochim. Acta 70, 5403-5425.

Christen F. and Busemann H. (2004) Solar noble gases in Vigarano bulk minerals - First results of the new "BENGEL" in-vacuo etching facility. Meteorit. Planet. Sci. Suppl. \#5188 (abstr.).

Clay P.L., King A., Wieler R. and Busemann H. (2012) Noble gas chronology of EH5 chondrite St. Mark's - an in-vacuo etch experiment. Planet. Sci. Suppl. \#5335 (abstr.).

Crowther S.A. and Gilmour J.D. (2013) The Genesis solar xenon composition and its relationship to planetary xenon signatures. Geochim. Cosmochim. Acta 123, 17-34.

Dauphas N., Marty B. and Reisberg L. (2002) Molybdenum nucleosynthetic dichotomy revealed in primitive meteorites. Astrophys. J. 569, 139-142. 
Delaney J.S., Turrin B. , Lindsay F. N., Park J., Herzog G. F., and Swisher C. C. III (2016) ${ }^{40} \mathrm{Ar}{ }^{39} \mathrm{Ar}$ ages vs. meteoroid depth in Murchison (CM2): A test of the solar heating hypothesis. Lunar Planet. Sci. XLVII, \#1569 (abstr.).

Eugster O. (1988) Cosmic-ray production-rates for ${ }^{3} \mathrm{He},{ }^{21} \mathrm{Ne},{ }^{38} \mathrm{Ar},{ }^{83} \mathrm{Kr}$, and ${ }^{126} \mathrm{Xe}$ in chondrites based on ${ }^{81} \mathrm{Kr}-\mathrm{Kr}$ exposure ages. Geochim. Cosmochim. Acta 52, 1649-1662.

Eugster O., Eberhardt P., Thalmann C.H., and Weigel A. (1998) Neon-E in CM-2 chondrite LEW90500 and collisional history of CM-2 chondrites, Maralinga, and other CK chondrites. Geochim. Cosmochim. Acta 62, 2573-2582.

Gilmour J.D., Verchovsky A.B. Fisenko A.V., Holland G., and Turner G. (2005) Xenon isotopes in size separated nanodiamonds from Efremovka: ${ }^{129} \mathrm{Xe} *$, Xe-P3, and Xe-P6. Geochim. Cosmochim. Acta 69, 4133-4148.

Gilmour J.D. (2010) "Planetary" noble gas components and the nucleosynthetic history of solar system material Geochim. Cosmochim. Acta 74, 380-393.

Gilmour J.D., Holland G., Verchovsky A.B., Fisenko A.V., Crowther S.A., and Turner G. (2016) Xenon and iodine reveal multiple distinct exotic xenon components in Efremovka "nanodiamonds". Geochim. Cosmochim. Acta 177, 78-93.

Grimberg A., Baur H., Bochsler P., Bühler F., Burnett D.S., Hays C.C., Heber V.S., Jurewicz A.J.G. and Wieler R. (2006) Solar wind neon from Genesis: Implications for the lunar noble gas record. Science 314, 1133-1135.

Gyngard F., Zinner E., Nittler L.R., Morgand A., Stadermann F.J. and Hynes K.M. (2010) Automated NanoSIMS measurements of spinel stardust from the Murray meteorite. Astrophys. J. 717, 107120.

Heber V.S., Baur H. and Wieler R. (2003) Helium in lunar samples analyzed by high-resolution stepwise etching: implications for the temporal constancy of solar wind isotopic composition. Astrophys. $J$. 597, 602-614.

Heber V.S., Wieler R., Baur H., Olinger C., Friedmann T.A. and Burnett D.S. (2009) Noble gas composition of the solar wind as collected by the Genesis mission. Geochim. Cosmochim. Acta 73, 7414-7432.

Heber V.S., Baur H., Bochsler P., McKeegan K.D., Neugebauer M., Reisenfeld D.B., Wieler R. and Wiens R.C. (2012) Isotopic mass fractionation of solar wind: Evidence from fast and slow solar wind collected by the genesis mission. Astrophys. J. 759, 121-134.

Hidaka H. and Yoneda S. (2011) Diverse nucleosynthetic components in barium isotopes of carbonaceous chondrites: Incomplete mixing of s- and r-process isotopes and extinct ${ }^{135} \mathrm{Cs}$ in the early solar system. Geochim. Cosmochim. Acta 75, 3687-3697.

Hilton D.R. and Porcelli D. (2014) Noble gases as tracers of mantle processes. In Treatise on Geochemistry, 2 ed. (eds. K.K. Turekian and H.D. Holland). Elsevier, Oxford. pp. 327-353.

Hohenberg C.M., Hudson B., Kennedy B. M. and Podosek F.A. (1981) Xenon spallation systematics in Angra dos Reis. Geochim. Cosmochim. Acta 45, 1909-1915.

Huss G.R. and Lewis R.S. (1994a) Noble-gases in presolar diamonds I: Three distinct components and their implications for diamond origins. Meteoritics 29, 791-810.

Huss G.R. and Lewis R.S. (1994b) Noble-gases in presolar diamonds II: Component abundances reflect thermal-processing. Meteoritics 29, 811-829.

Huss G.R. and Lewis R.S. (1995). Presolar diamond, SiC, and graphite in primitive chondrites: Abundances as a function of meteorite class and petrologic type. Geochim. Cosmochim. Acta 59, 115-160.

Huss G.R., Lewis R.S. and Hemkin S. (1996) The "normal planetary" noble gas component in primitive chondrites: Compositions, carrier, and metamorphic history. Geochim. Cosmochim. Acta 60, 3311-3340.

Huss G.R., Meshik A.P., Smith J.B. and Hohenberg C.M. (2003) Presolar diamond, silicon carbide, and graphite in carbonaceous chondrites: Implications for thermal processing in the solar nebula. Geochim. Cosmochim. Acta 67, 4823-4848. 
Hynes K.M. and Gyngard F. (2009) The presolar grain database: http://presolar.wustl..edu/ pgd. Lunar Planet. Sci. XL, \#1198 (abstr.).

Jeffery P.M. and Anders E. (1970) Primordial noble gases in separated meteoritic minerals -1. Geochim. Cosmochim. Acta 34, 1175-1198.

King A., Clay P.L., Crowther S.A., Nottingham M., Gilmour J.D., Wieler R. and Busemann H. (2013) Noble gas chronology of EH3 chondrite ALHA77295 by Closed System Stepped Etching. Lunar Planet. Sci. XLIV, \#2217 (abstr.).

Knotter D.M. and Denteneer T.J.J. (2001) Etching mechanism of silicon nitride in HF-based solutions. $J$. Electrochem. Soc. 148, F43-F46.

Krot A.N., Keil K., Scott E.R.D., Goodrich C.A. and Weisberg M.K. (2014) Classification of meteorites and their genetic relationships. In Treatise on Geochemistry, 2nd ed. (eds. K.K. Turekian and H.D. Holland). Elsevier, Oxford, pp. 1-63.

Leitner J., Vollmer C., Floss C., Zipfel J. and Hoppe P. (2016) Ancient stardust in fine-grained chondrule dust rims from carbonaceous chondrites. Earth Planet. Sci. Lett. 434, 117-128.

Lewis R.S. and Srinivasan B. (1993) A search for noble-gas evidence for presolar oxide grains. Lunar Planet. Sci. XXIV, \#1438 (abstr.).

Lewis R.S., Srinivasan B. and Anders E. (1975) Host phase of a strange Xenon component in Allende. Science 190, 1251-1262.

Lewis R.S., Ming T., Wacker J.F., Anders E. and Steel E. (1987) Interstellar diamonds in meteorites. Nature 326, 160-162.

Lewis R.S., Amari S. and Anders E. (1994) Interstellar grains in meteorites. II. SiC and its noble gases. Geochim. Cosmochim. Acta 58, 471-494.

Lin Y.T., Amari S. and Pravdivtseva O. (2002) Presolar grains from the Qingzhen (EH3) meteorite. Astrophys. J. 575, 257-263.

Lodders K. and Fegley B. (1998) The Planetary Scientist's Companion. Oxford University Press, Inc., New York.

Lugmair G.W. and Marti K. (1977) Sm-Nd-Pu time pieces in Angra-dos-Reis Meteorite. Earth Planet. Sci. Lett. 35, 273-284.

Marrocchi Y., Avice G. and Estrade N. (2015) Multiple carriers of Q noble gases in primitive meteorites. Geophys. Res. Lett. 42, 2093-2099.

Mason B. and Graham A.L. (1970) Minor and trace elements in meteoritic minerals. Smithsonian Contr. Earth Sci. 3, 1-17.

Matsuda J.-I., Lewis R.S., Takahashi H. and Anders E. (1980) Isotopic anomalies of noble gases in meteorites and their origins-VII. C3V carbonaceous chondrites. Geochim. Cosmochim. Acta 44, 1861-1874.

Mazor E., Heymann D. and Anders E. (1970) Noble gases in carbonaceous. Geochim. Cosmochim. Acta 34, 781-824.

Meshik A., Hohenberg C., Pravdivtseva O. and, Burnett D. (2014) Heavy noble gases in solar wind delivered by Genesis mission. Geochim. Cosmochim. Acta 127, 326-347.

Morlok A., Bischoff A., Stephan T., Floss C., Zinner E. and Jessberger E.K. (2006) Brecciation and chemical heterogeneities of CI chondrites. Geochim. Cosmochim. Acta 70, 5371-5394.

Murer C.A., Baur H., Signer P. and Wieler R. (1997) Helium, neon, and argon abundances in the solar wind: In vacuo etching of meteoritic iron-nickel. Geochim. Cosmochim. Acta 61, 1303-1314.

Nakamura T., Nagao K., Metzler K. and Takaoka N. (1999) Heterogeneous distribution of solar and cosmogenic noble gases in CM chondrites and implications for the formation of CM parent bodies. Geochim. Cosmochim. Acta 63, 257-273.

Nguyen A.N. and Zinner E. (2004) Discovery of ancient silicate stardust in a meteorite. Science 303, 1496-1499.

Nittler L.R. and Alexander C.M.O'D. (2003) Automated isotopic measurements of micron-sized dust: Application to meteoritic presolar silicon carbide. Geochim. Cosmochim. Acta 67, 4961-4980. 
Nittler L.R., Alexander C.M.O’D., Gao X., Walker R.M. and Zinner E.K. (1994) Interstellar oxide grains from the Tieschitz ordinary chondrite. Nature 370, 443-446.

Nittler L.R., Hoppe P., Alexander C.M.O'D., Amari S., Eberhardt P., Gao X., Lewis R.S., Strebel R., Walker R.M. and Zinner E. (1995) Silicon-nitride from supernovae. Astrophys. J. 453, L25-L28.

Nittler L.R., Alexander C.M.O'D., Gao X., Walker R.M. and Zinner E. (1997) Stellar sapphires: The properties and origins of presolar $\mathrm{Al}_{2} \mathrm{O}_{3}$ in meteorites. Astrophys. J. 483, 475-495.

Nittler L.R., Alexander C.M.O'D., Wang J. and Gao X. (1998) Meteoritic oxide grain from supernova found. Nature 393, 222-223.

Ott U. (1996) Interstellar diamond xenon and timescales of supernova ejecta. Astrophys. J. 463, 344-348.

Ott U. (2014) Planetary and pre-solar noble gases in meteorites. Chemie der Erde-Geochem. 74, 519544.

Ozima M., Wieler R., Marty B., and Podoske F.A. (1998) Comparative studies of solar, Q-gases and terrestrial noble gases, and implication of the evolution of the solar nebula. Geochim. Cosmochim. Acta 62, 301-314.

Paton C., Schiller M. and Bizzarro M. (2013) Identification of an ${ }^{84} \mathrm{Sr}$-depleted carrier in primitive meteorites and implications for thermal processing in the solar protoplanetary disk. Astrophys. $J$. 763, 40-46.

Pedroni A. and Begemann F. (1994) On unfractionated solar noble-gases in the H3-6 meteorite Acfer 111. Meteoritics 29, 632-642.

Ragettli R.A., Hebeda E.H., Signer P., Wieler R. (1994) Uranium-xenon chronology: Precise determination of $\mathrm{a}_{\mathrm{sf}}{ }^{* 136} \mathrm{Y}_{\mathrm{sf}}$ for spontaneous fission of ${ }^{238} \mathrm{U}$. Earth Planet. Sci. Lett. 128, 653-670

Reisberg L., Dauphas N., Luguet A., Pearson D.G., Gallino R. and Zimmermann C. (2009) Nucleosynthetic osmium isotope anomalies in acid leachates of the Murchison meteorite. Earth Planet. Sci. Lett. 277, 334-344.

Reynolds J.H. (1960) Determination of the age of the elements. Phys. Rev. Lett. 4, 8-10.

Schelhaas N., Ott U. and Begemann F. (1990) Trapped noble gases in unequilibrated ordinary chondrites. Geochim. Cosmochim. Acta 54, 2869-2882.

Schönbächler M., Rehkämper M., Fehr M.A., Halliday A.N., Hattendorf B. and Günther D. (2005) Nucleosynthetic zirconium isotope anomalies in acid leachates of carbonaceous chondrites. Geochim. Cosmochim. Acta 69, 5113-5122.

Signer P., Baur H. and Wieler R. (1993) Closed system stepped etching; an alternative to stepped heating. In Alfred 0. Nier Symposium on Inorganic Mass Spectrometry (ed. D. J. Rokof). Los Alamos National Laboratory, Durango, Colorado, USA. pp. 181-202.

Stauffer H. (1961) Primordial argon and neon in carbonaceous chondrites and ureilites. Geochim. Cosmochim. Acta 24, 70-82.

Stroud R.M., Chisholm M.F., Heck P.R., Alexander C.M.O'D., and Nittler L.R. (2011). Supernova shockwave-induced co-formation of glassy carbon and nanodiamond. Astrophys. J. Lett. 738, L27-32.

Turrin B., Lindsay F. N., Park J., Herzog G. F., Delaney J.S and Swisher C. C. III (2014) ${ }^{40} \mathrm{Ar} /{ }^{39} \mathrm{Ar}$ studies of Murchison (CM2) and Tagish Lake (C2-ung.). Lunar Planet. Sci. XLV, \#2485 (abstr.).

Wieler R. 2002. Cosmic-ray-produced noble gases in meteorites. In Noble gases in geochemistry and cosmochemistry, (eds. D. Porcelli, C.J. Ballentine, and R. Wieler). The Mineralogical Society of America, Washington DC. pp. 125-170.

Wieler R., Baur H. and Signer P. (1986) Noble-gases from solar energetic particles revealed by Closed System Step Etching of lunar soil minerals. Geochim.Cosmochim. Acta 50, 1997-2017.

Wieler R., Pedroni A. and Leya I. (2000) Cosmogenic neon in mineral separates from Kapoeta: No evidence for an irradiation of its parent body regolith by an early active Sun. Meteorit. Planet. Sci. 35, 251-257.

Wielet R. (2016) Do lunar and meteoritic archives record temporal variations in the composition of solar wind noble gases and nitrogen? A reassessment in the light of Genesis data. Chemie der Erde 76, 463-480. 
Zinner E. (2014) Presolar Grains. In Treatise on Geochemistry, 2 ed. (eds. K.K. Turekian and H.D. Holland). Elsevier, Oxford. pp. 181-213.

Zinner E., Tang M. and Anders E. (1987) Large isotopic anomalies of Si, C, N and noble-gases in interstellar silicon-carbide from the Murray meteorite. Nature 330, 730-732.

Zinner E., Amari S., Guinness R., Jennings C., Mertz A.F., Nguyen A.N., Gallino R., Hoppe P., Lugaro M., Nittler L.R. and Lewis R.S. (2007) NanoSIMS isotopic analysis of small presolar grains: Search for $\mathrm{Si}_{3} \mathrm{~N}_{4}$ grains from AGB stars and $\mathrm{Al}$ and Ti isotopic compositions of rare presolar $\mathrm{SiC}$ grains. Geochim. Cosmochim. Acta 71, 4786-4813. 


\section{Figure captions}

Fig 1. Neon three isotope plot. Panel B is an enlarged version of the upper left corner of panel A. Neon in the etch steps in part 1 of the etch run are a mixture of fractionated SW (Ne-fSW) and cosmogenic Ne. Most of the etch steps in part 2 also released $\mathrm{Ne}$ in agreement with a mixture of $\mathrm{Ne}-\mathrm{fSW}$ and cosmogenic Ne, with larger relative contribution of the cosmogenic endmember than the steps in part 1 . However, steps 12,13,16, and 18 contain at least one component in addition to Ne-fSW and cosmogenic Ne. The etch steps in part 3 are essentially devoid of cosmogenic $\mathrm{Ne}$ and have a lower ${ }^{20} \mathrm{Ne} /{ }^{22} \mathrm{Ne}$ ratio than $\mathrm{fSW}$. It is, therefore, clear that the $\mathrm{Ne}$ in the HF-solubles of Ivuna contains primordial Ne. The composition of this component, corrected for Ne-SW based on the concentration of He, is shown as Ivuna Ne $e_{t r}$ in panel B. Also shown are the compositions of all Ne released in the etch run Ivuna total etch, and Ne released in one step pyrolysis of the bulk sample Ivuna bulk.

Fig. 2. The evolution of the ${ }^{3} \mathrm{He} /{ }^{4} \mathrm{He}$ ratio throughout the etch run. The He in etch steps in part 1 has ${ }^{3} \mathrm{He} /{ }^{4} \mathrm{He}$ ratios that agree well with the ratio for SW. In part 2 there is a clear contribution of cosmogenic ${ }^{3} \mathrm{He}$. Surprisingly, the He released in part 3 of the etch run again have ${ }^{3} \mathrm{He} /{ }^{4} \mathrm{He}$ ratios similar to the SW.

Fig 3. ${ }^{4} \mathrm{He} /{ }^{36} \mathrm{Ar} v{ }^{20} \mathrm{Ne}^{36} \mathrm{Ar}$. Panel a shows that the first 10 etch steps (part 1) have high ${ }^{4} \mathrm{He} /{ }^{36} \mathrm{Ar}$ and ${ }^{20} \mathrm{Ne} /{ }^{36} \mathrm{Ar}$ ratios, compatible with contributions from SW. The first 4 etch steps have lower ${ }^{4} \mathrm{He} /{ }^{20} \mathrm{Ne}$ ratios, possibly related to He-loss from the outermost layers of the grains. Panel b shows the lower left corner of panel a. The later etch steps have lower elemental ratios indicating that the SW seen in the first 10 etch steps was less prominent and that other, elementally heavier components were more dominating. Also shown is the total of the gases released in the etch run and during pyrolysis of the bulk sample. 
Fig. 4. Evolution of the $\left({ }^{4} \mathrm{He} /{ }^{20} \mathrm{Ne}\right)$ tr ratio over the etch run. The first steps had low ratios, potentially due to some He-loss. Remarkably, in steps 7-9 the ratio was similar to the unfractionated SW value and thereafter the ratio decreased to a more fractionated value. In contrast to ${ }^{3} \mathrm{He} /{ }^{4} \mathrm{He}$ (Fig. 2), ${ }^{4} \mathrm{He} /{ }^{20} \mathrm{Ne}$ in part 3 did not show a SW signature.

Fig. 5. Cumulative release pattern of major elements (a) and of radiogenic, SW, and cosmogenic components (b) throughout the etch run. Most of the He and Ne was released in the first part of the etch run, whereas $\mathrm{Ar}, \mathrm{Kr}$, and Xe increased steadily throughout the etch run. In panel $\mathrm{b}$ it can be seen that most of the SW-like noble gases were released in the first part of the etch run whereas about half of the cosmogenic $\mathrm{Ne}$ is released in the first part of the etch run and half in the second part. The concentration of ${ }^{129} \mathrm{Xe}_{\text {rad }}$ was determined based on the average mixture of air and Q for the different parts of the etch run (see Fig. 7).

Fig. 6. Argon isotopic composition. All endmembers except air are plotted as lines in this diagram since they are theoretically devoid of ${ }^{40}$ Ar. Argon-40 is, however, present in the sample from radiogenic decay of ${ }^{40} \mathrm{~K}$ and from atmospheric contamination. Most steps in part 1 (black squares) released $\mathrm{Ar}$ with ${ }^{36} \mathrm{Ar} /{ }^{38} \mathrm{Ar}$ ratios roughly in agreement with $\mathrm{SW}$; in the later steps of part 1 small contributions of cosmogenic Ar can be seen. Most of the steps in part 2 (grey triangles) show significant contributions of cosmogenic Ar. In part 3 (light grey circles) the etch steps released Ar with ${ }^{36} \mathrm{Ar} /{ }^{38} \mathrm{Ar}$ ratios in agreement with $\mathrm{Q}$. 
Fig. 7. Xenon isotopic compositions in the three parts of the etch run (panels a, b and, c) as well as in the bulk pyrolysis sample (panel d) normalized to ${ }^{132} \mathrm{Xe}$ and atmospheric Xe. In part 1 (a) the Xe isotopic composition agrees with a mixture of $20 \% \mathrm{Q}$ and $80 \%$ air. In addition to this, the ${ }^{129} \mathrm{Xe} /{ }^{132} \mathrm{Xe}$ ratio is elevated due to decay of the now extinct isotope ${ }^{129} \mathrm{I}$. Elevated ${ }^{129} \mathrm{Xe} /{ }^{132} \mathrm{Xe}$ is also seen in part 2 of the etch run (b). Part 2 has a higher relative abundance of trapped Xe than part 1, in agreement with $50 \% \mathrm{Q}$ and $50 \%$ air. In addition to this, a clear cosmogenic signal is seen in the Xe isotopes in part 2, in agreement with $\sim 7 \%$ of the ${ }^{126} \mathrm{Xe}$ measured being cosmogenic. In part 3 of the etch run (c) the Xe isotopic composition is roughly in agreement with a mixture of $50 \% \mathrm{Q}$ and $50 \%$ air (note that the scale is different in this plot compared to the other three). However, the lightest and the heaviest isotopic ratios do not agree with this mixture. We, therefore, suggest that small amounts $\left(\sim 3 \%\right.$ of $\left.{ }^{132} \mathrm{Xe}\right)$ could be Xe-HL. As expected, the gases released on pyrolysis of the bulk sample (d) has a Xe isotopic composition roughly in agreement with Q. The data fit a model of $98.5 \% \mathrm{Q}$ and $1.5 \% \mathrm{HL}$ based on ${ }^{132} \mathrm{Xe}$ very well.

Fig. 8. Xenon three isotope plot illustrating the ${ }^{129} \mathrm{Xe}$ excess. For simplicity, the uncertainties on ${ }^{130} \mathrm{Xe} /{ }^{132} \mathrm{Xe}$ and the individual steps numbers are not included in the figure. In the gases released during pyrolysis of the bulk sample ${ }^{129} \mathrm{Xe} /{ }^{132} \mathrm{Xe}$ is identical to $\mathrm{Q}$ and the concentration of ${ }^{129} \mathrm{Xe}_{\mathrm{rad}}$ could not be determined. Gases in part 2 have the highest ${ }^{129} \mathrm{Xe} /{ }^{132} \mathrm{Xe}$ ratios, in part 1 only slightly lower and part 3 significantly lower, in agreement with Q and air. Step 2 is not included in this figure as it falls outside of the range, however, uncertainties on this step are significant and it is within uncertainties in the same range as the other steps. 
Table 1. Noble gas components discussed in the paper. Shaded fields in the last columns indicate that the noble gas component was detected.

\begin{tabular}{|c|c|c|c|c|c|c|c|c|}
\hline & \multirow[t]{2}{*}{ Name } & \multirow[t]{2}{*}{ Carrier(s) } & \multirow[t]{2}{*}{ Process } & \multirow[t]{2}{*}{ Noble gas characteristics } & \multirow[t]{2}{*}{ Occurs in } & \multicolumn{3}{|c|}{$\begin{array}{l}\text { Occurs in Ivuna } \\
\text { CSSE part }\end{array}$} \\
\hline & & & & & & 1 & 2 & 3 \\
\hline \multirow{4}{*}{ 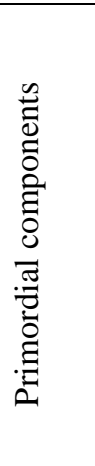 } & Q & $\begin{array}{l}\text { Phase } Q \text { - unidentified } \\
\text { phase }(\mathrm{s}) \text {, likely carbonaceous }\end{array}$ & $\begin{array}{l}\text { Still under debate. Can be } \\
\text { explained by fractionated } \\
\mathrm{SW}+\mathrm{HL}+{ }^{129} \mathrm{Xe}_{\mathrm{rad}}^{\#}\end{array}$ & $\begin{array}{l}\text { All noble gases, fractionated } \\
\text { relative to solar } \\
\text { Main carrier of heavy primordial } \\
\text { noble gases Ar-Xe }\end{array}$ & $\begin{array}{l}\text { All un-equilibrated } \\
\text { chondrites, some } \\
\text { achondrites }\end{array}$ & & & \\
\hline & $\mathrm{Ne}-\mathrm{E}$ & Presolar graphite, $\mathrm{SiC}$ & S-process and R-process & Monoisotopic ${ }^{22} \mathrm{Ne}$ & Type 1-3(4) & & & \\
\hline & HL & Presolar nanodiamonds* & $\begin{array}{l}\text { R-process and P-process } \\
(+\mathrm{S} \text {-process) }\end{array}$ & $\begin{array}{l}\text { All noble gases. } \\
\text { Majority of primordial } \mathrm{He} \text { and } \mathrm{Ne} \\
\text { in primitive meteorites. } \\
\text { Exotic } \mathrm{Xe} \text { composition }\end{array}$ & Type $1-3$ & & & \\
\hline & $\mathrm{P} 3$ & Presolar nanodiamonds* & S-, P-, R-process & $\begin{array}{l}\text { Similar to } \mathrm{Q}, \\
\text { S-process deficit compared to Q }\end{array}$ & Type 1-3 & & & \\
\hline \multirow{3}{*}{ 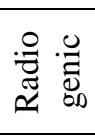 } & Fission-Xe & Minerals containing $\mathrm{Pu}, \mathrm{U}$ & Spontaneous fission & Heavy $\mathrm{Xe}$ isotopes & All meteorites & & & \\
\hline & ${ }^{40} \mathrm{Ar}_{\mathrm{rad}}$ & Minerals containing $\mathrm{K}$ & Decay of ${ }^{40} \mathrm{~K}\left(\mathrm{~T}_{1 / 2}=1.28 \mathrm{Gyr}\right)$ & ${ }^{40} \mathrm{Ar}$ & All meteorites & & & \\
\hline & ${ }^{129} \mathrm{Xe}_{\mathrm{rad}}$ & Minerals containing I & Decay of ${ }^{129} \mathrm{I}\left(\mathrm{T}_{1 / 2}=16 \mathrm{Myr}\right)$ & ${ }^{129} \mathrm{Xe}$ & All meteorites & & & \\
\hline 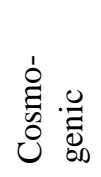 & & $\begin{array}{l}\text { Minerals containing target } \\
\text { elements } \\
\text { (Ne-mainly } \mathrm{Mg}, \mathrm{Si} \text {; } \\
\mathrm{Xe} \text {-mainly } \mathrm{Ba}, \mathrm{REE})\end{array}$ & $\begin{array}{l}\text { Nuclear reactions by cosmic } \\
\text { rays }\end{array}$ & $\begin{array}{l}\text { Most prominent cosmogenic } \\
\text { isotopes: } \\
{ }^{3} \mathrm{He},{ }^{21} \mathrm{Ne},{ }^{38} \mathrm{Ar},{ }^{78,80,82,83} \mathrm{Kr} \text {, } \\
{ }^{124,126} \mathrm{Xe}\end{array}$ & All meteorites & & & \\
\hline 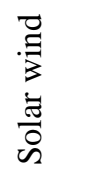 & SW & $\begin{array}{l}\text { Top nm of grains exposed on } \\
\text { the surface of asteroid }\end{array}$ & $\begin{array}{l}\text { Implantation of SW emitted } \\
\text { from the sun }\end{array}$ & Mainly light noble gases $\mathrm{He}-\mathrm{Ne}$ & Regolith breccias & & & \\
\hline
\end{tabular}

Refs: Busemann et al. (2000); Huss and Lewis (1995); Huss et al. (1996); Huss et al. (2003); Ott (2014); Wieler (2002); Wieler (2016); and references therein *Nanodiamond-rich separates also contain glassy carbon (Stroud et al., 2011)

\# Gilmour (2010), Crowther and Gilmour (2013), see also Meshik et al. (2014) who in addition suggested the presence of some S-process isotopes 
Table 2. Etching conditions for individual steps in the CSSE analysis as well as He and Ne concentrations and isotopic composition for all etch steps, total gas released in the CSSE

\begin{tabular}{|c|c|c|c|c|c|c|c|}
\hline Step & Etching conditions & Etching time & $\begin{array}{c}{ }^{4} \mathrm{He} \\
{\left[10^{-8} \mathrm{~cm}^{3} \mathrm{STP} / \mathrm{g}\right]}\end{array}$ & $\begin{array}{c}{ }^{3} \mathrm{He} /{ }^{4} \mathrm{He} \\
{\left[10^{-4}\right]}\end{array}$ & $\begin{array}{c}{ }^{20} \mathrm{Ne} \\
{\left[10^{-8} \mathrm{~cm}^{3} \mathrm{STP} / \mathrm{g}\right]}\end{array}$ & ${ }^{21} \mathrm{Ne} /{ }^{20} \mathrm{Ne}$ & ${ }^{22} \mathrm{Ne} /{ }^{20} \mathrm{Ne}$ \\
\hline 1 & Vapor & $15 \mathrm{~min}$ & $316 \pm 6$ & $3.88 \pm 0.03$ & $5.1 \pm 0.1$ & $0.00966 \pm 0.00005$ & $0.0930 \pm 0.0002$ \\
\hline 2 & Residual step 1 & - & $11.0 \pm 0.2$ & $4.15 \pm 0.10$ & $0.162 \pm 0.004$ & $0.0100 \pm 0.0003$ & $0.0936 \pm 0.0009$ \\
\hline 3 & Vapor & $15 \mathrm{~min}$ & $401 \pm 8$ & $4.10 \pm 0.03$ & $1.40 \pm 0.03$ & $0.0150 \pm 0.0001$ & $0.0985 \pm 0.0002$ \\
\hline 4 & Vapor & $20 \mathrm{~min}$ & $686 \pm 14$ & $4.01 \pm 0.02$ & $1.53 \pm 0.04$ & $0.0165 \pm 0.0001$ & $0.0974 \pm 0.0004$ \\
\hline 5 & Vapor & $35 \mathrm{~min}$ & $1030 \pm 21$ & $3.87 \pm 0.02$ & $1.86 \pm 0.05$ & $0.01423 \pm 0.00009$ & $0.0933 \pm 0.0002$ \\
\hline 6 & Vapor & $1 \mathrm{~h}$ & $1430 \pm 29$ & $3.72 \pm 0.02$ & $2.33 \pm 0.06$ & $0.01420 \pm 0.00004$ & $0.0931 \pm 0.0003$ \\
\hline 7 & Vapor & $1.5 \mathrm{~h}$ & $1660 \pm 34$ & $3.63 \pm 0.02$ & $2.52 \pm 0.06$ & $0.01385 \pm 0.00006$ & $0.0930 \pm 0.0002$ \\
\hline 8 & Vapor & $2 \mathrm{~h}$ & $1560 \pm 32$ & $3.54 \pm 0.02$ & $2.34 \pm 0.06$ & $0.01508 \pm 0.00005$ & $0.0959 \pm 0.0002$ \\
\hline 9 & Vapor & $3.5 \mathrm{~h}$ & $1440 \pm 29$ & $3.58 \pm 0.02$ & $2.17 \pm 0.06$ & $0.02045 \pm 0.00009$ & $0.1027 \pm 0.0002$ \\
\hline 10 & Vapor & $13.5 \mathrm{~h}$ & $1150 \pm 23$ & $4.51 \pm 0.02$ & $1.87 \pm 0.05$ & $0.0394 \pm 0.0001$ & $0.1256 \pm 0.0004$ \\
\hline 11 & Vapor & $117 \mathrm{~h}$ & $818 \pm 17$ & $9.57 \pm 0.04$ & $1.77 \pm 0.05$ & $0.1082 \pm 0.0002$ & $0.2046 \pm 0.0005$ \\
\hline 12 & Residual step 11 & - & $7.5 \pm 0.2$ & $9.53 \pm 0.09$ & $0.034 \pm 0.001$ & $0.0597 \pm 0.0007$ & $0.186 \pm 0.002$ \\
\hline 13 & Mini distill ${ }^{\circ} 35 \mathrm{~min}$ & $3 \mathrm{~h}$ & $3.31 \pm 0.08$ & $9.1 \pm 0.3$ & $0.0104 \pm 0.0003$ & $0.089 \pm 0.001$ & $0.212 \pm 0.005$ \\
\hline 14 & Mini distill $^{\circ} 8 \mathrm{~h}$ & $1.5 \mathrm{~h}$ & $52 \pm 1$ & $20.9 \pm 0.1$ & $0.128 \pm 0.003$ & $0.230 \pm 0.001$ & $0.337 \pm 0.002$ \\
\hline 15 & Mini distill ${ }^{\circ} 17 \mathrm{~h}$ & $2 \mathrm{~h}$ & $47.2 \pm 1.0$ & $30.1 \pm 0.2$ & $0.125 \pm 0.003$ & $0.161 \pm 0.001$ & $0.253 \pm 0.001$ \\
\hline 16 & No new acid & $14 \mathrm{~h}$ & $13.6 \pm 0.3$ & $16.6 \pm 0.1$ & $0.092 \pm 0.003$ & $0.0290 \pm 0.0008$ & $0.125 \pm 0.002$ \\
\hline 17 & Mini distill ${ }^{\circ} 14 \mathrm{~h}$ & $3.5 \mathrm{~h}$ & $18.1 \pm 0.4$ & $26.5 \pm 0.3$ & $0.060 \pm 0.002$ & $0.1308 \pm 0.0009$ & $0.228 \pm 0.002$ \\
\hline 18 & No new acid & $17 \mathrm{~h}$ & $9.6 \pm 0.2$ & $6.7 \pm 0.1$ & $0.084 \pm 0.002$ & $0.0083 \pm 0.0001$ & $0.107 \pm 0.001$ \\
\hline 19 & Acid distill $^{+}$ & - & $0.18 \pm 0.07$ & $23 \pm 8$ & $0.0005 \pm 0.0001$ & $0.08 \pm 0.03$ & $0.4 \pm 0.1$ \\
\hline 20 & Liquid & $4 \mathrm{~h}$ & $11.9 \pm 0.2$ & $24.9 \pm 0.2$ & $0.045 \pm 0.001$ & $0.091 \pm 0.001$ & $0.184 \pm 0.002$ \\
\hline 21 & Liquid & $37 \mathrm{~h}$ & $11.3 \pm 0.2$ & $4.51 \pm 0.04$ & $0.140 \pm 0.002$ & $0.00382 \pm 0.00008$ & $0.100 \pm 0.001$ \\
\hline 22 & Liquid, $50^{\circ} \mathrm{C}$ & $3 \mathrm{~h}$ & $3.13 \pm 0.08$ & $3.4 \pm 0.2$ & $0.0289 \pm 0.0008$ & $0.0037 \pm .0001$ & $0.107 \pm 0.002$ \\
\hline 23 & Liquid, $60^{\circ} \mathrm{C}$ & $11.5 \mathrm{~h}$ & $11.6 \pm 0.2$ & $3.6 \pm 0.1$ & $0.128 \pm 0.003$ & $0.0039 \pm 0.0002$ & $0.0998 \pm 0.0006$ \\
\hline 24 & Liquid, $60^{\circ} \mathrm{C}$ & $72 h$ & $35.0 \pm 0.7$ & $3.39 \pm 0.05$ & $1.885 \pm 0.038$ & $0.00302 \pm 0.00004$ & $0.1068 \pm 0.0003$ \\
\hline 25 & Liquid, $70^{\circ} \mathrm{C}$ & $14.5 \mathrm{~h}$ & $2.05 \pm 0.05$ & $3.9 \pm 0.2$ & $0.036 \pm 0.001$ & $0.0031 \pm 0.0002$ & $0.107 \pm 0.002$ \\
\hline 26 & Liquid, $90^{\circ} \mathrm{C}$ & $18 \mathrm{~h}$ & $6.0 \pm 0.1$ & $4.1 \pm 0.2$ & $0.041 \pm 0.001$ & $0.0042 \pm 0.0003$ & $0.116 \pm 0.001$ \\
\hline 27 & Liquid, $100^{\circ} \mathrm{C}$ & $84 \mathrm{~h}$ & $64.8 \pm 1.3$ & $3.77 \pm 0.04$ & $0.62 \pm 0.01$ & $0.00350 \pm 0.00009$ & $0.1203 \pm 0.0004$ \\
\hline Total* & & & $10762 \pm 73$ & $4.53 \pm 0.04$ & $24.6 \pm 0.2$ & $0.0247 \pm 0.0003$ & $0.109 \pm 0.001$ \\
\hline Bulk & & & $18301 \pm 391$ & $3.59 \pm 0.04$ & $45 \pm 1$ & $0.0164 \pm 0.0001$ & $0.121 \pm 0.001$ \\
\hline
\end{tabular}

Mini distill: sample kept at $-15^{\circ} \mathrm{C}$ and acid at room temperature for the time given in the table. The

${ }^{+}$Acid distill: The acid was fully transferred to the sample volume by heating the acid to $80-90^{\circ} \mathrm{C}$ and cooling the sample to $-60^{\circ} \mathrm{C}$ for $2 \mathrm{~h}$

*excluding steps 24 and 25 which suffered from atmospheric contamination (see main text) and the acid distill step 19. 
Table 3. Argon and $\mathrm{Kr}$ concentrations and isotopic composition for all etch steps, total gas released in the CSSE analysis, and the bulk sample measured in the furnace.

\begin{tabular}{|c|c|c|c|c|c|c|c|c|}
\hline Step & $\begin{array}{c}{ }^{36} \mathrm{Ar} \\
{\left[10^{-8} \mathrm{~cm}^{3} \mathrm{STP} / \mathrm{g}\right]}\end{array}$ & ${ }^{38} \mathrm{Ar} /{ }^{36} \mathrm{Ar}$ & ${ }^{40} \mathrm{Ar} /{ }^{36} \mathrm{Ar}$ & $\begin{array}{c}{ }^{84} \mathrm{Kr} \\
{\left[10^{-11} \mathrm{~cm}^{3} \mathrm{STP} / \mathrm{g}\right]}\end{array}$ & ${ }^{80} \mathrm{Kr} /{ }^{84} \mathrm{Kr}$ & ${ }^{82} \mathrm{Kr} /{ }^{84} \mathrm{Kr}$ & ${ }^{83} \mathrm{Kr} /{ }^{84} \mathrm{Kr}$ & ${ }^{86} \mathrm{Kr} /{ }^{84} \mathrm{Kr}$ \\
\hline 1 & $0.407 \pm 0.008$ & $0.1779 \pm 0.0010$ & $120.7 \pm 0.7$ & $8.32 \pm 0.22$ & $0.0415 \pm 0.0006$ & $0.204 \pm 0.002$ & $0.201 \pm 0.002$ & $0.304 \pm 0.002$ \\
\hline $2^{+}$ & $0.0157 \pm 0.0003$ & $0.1815 \pm 0.0020$ & $170 \pm 3$ & $0.34 \pm 0.01$ & $0.0392 \pm 0.0022$ & $0.208 \pm 0.011$ & $0.196 \pm 0.009$ & $0.296 \pm 0.010$ \\
\hline 3 & $0.201 \pm 0.004$ & $0.1819 \pm 0.0009$ & $81.4 \pm 0.5$ & $3.62 \pm 0.09$ & $0.0416 \pm 0.0006$ & $0.206 \pm 0.002$ & $0.203 \pm 0.002$ & $0.309 \pm 0.005$ \\
\hline 4 & $0.254 \pm 0.005$ & $0.1805 \pm 0.0007$ & $69.4 \pm 0.4$ & $4.38 \pm 0.11$ & $0.0417 \pm 0.0006$ & $0.206 \pm 0.002$ & $0.202 \pm 0.002$ & $0.315 \pm 0.003$ \\
\hline 5 & $0.272 \pm 0.005$ & $0.1808 \pm 0.0007$ & $63.8 \pm 0.3$ & $4.68 \pm 0.12$ & $0.0419 \pm 0.0005$ & $0.201 \pm 0.003$ & $0.200 \pm 0.003$ & $0.307 \pm 0.002$ \\
\hline 6 & $0.347 \pm 0.007$ & $0.1821 \pm 0.0009$ & $64.3 \pm 0.3$ & $6.04 \pm 0.15$ & $0.0402 \pm 0.0007$ & $0.199 \pm 0.002$ & $0.198 \pm 0.002$ & $0.302 \pm 0.003$ \\
\hline 7 & $0.341 \pm 0.007$ & $0.1838 \pm 0.0009$ & $67.8 \pm 0.4$ & $6.18 \pm 0.18$ & $0.0410 \pm 0.0006$ & $0.207 \pm 0.003$ & $0.199 \pm 0.003$ & $0.307 \pm 0.004$ \\
\hline 8 & $0.334 \pm 0.007$ & $0.1841 \pm 0.0010$ & $73.8 \pm 0.4$ & $6.18 \pm 0.17$ & $0.0419 \pm 0.0008$ & $0.204 \pm 0.003$ & $0.198 \pm 0.003$ & $0.304 \pm 0.004$ \\
\hline 9 & $0.376 \pm 0.008$ & $0.1863 \pm 0.0008$ & $73.6 \pm 0.3$ & $7.39 \pm 0.20$ & $0.0410 \pm 0.0006$ & $0.200 \pm 0.003$ & $0.205 \pm 0.003$ & $0.307 \pm 0.004$ \\
\hline 10 & $0.59 \pm 0.01$ & $0.1915 \pm 0.0008$ & $75.5 \pm 0.8$ & $11.69 \pm 0.29$ & $0.0410 \pm 0.0004$ & $0.204 \pm 0.002$ & $0.201 \pm 0.002$ & $0.311 \pm 0.002$ \\
\hline 11 & $1.72 \pm 0.03$ & $0.2052 \pm 0.0008$ & $89.7 \pm 0.4$ & $37.47 \pm 0.95$ & $0.0425 \pm 0.0005$ & $0.202 \pm 0.002$ & $0.199 \pm 0.002$ & $0.304 \pm 0.002$ \\
\hline 12 & $0.0717 \pm 0.0003$ & $0.1886 \pm 0.0010$ & $229 \pm 1$ & $2.37 \pm 0.06$ & $0.0394 \pm 0.0006$ & $0.202 \pm 0.004$ & $0.204 \pm 0.002$ & $0.309 \pm 0.005$ \\
\hline 13 & $0.0309 \pm 0.0001$ & $0.1988 \pm 0.0015$ & $149 \pm 2$ & $2.26 \pm 0.06$ & $0.0437 \pm 0.0006$ & $0.205 \pm 0.004$ & $0.208 \pm 0.003$ & $0.300 \pm 0.005$ \\
\hline 14 & $0.177 \pm 0.004$ & $0.2302 \pm 0.0011$ & $137.2 \pm 0.7$ & $5.80 \pm 0.15$ & $0.0418 \pm 0.0006$ & $0.202 \pm 0.003$ & $0.206 \pm 0.003$ & $0.309 \pm 0.003$ \\
\hline 15 & $0.411 \pm 0.008$ & $0.2413 \pm 0.0013$ & $128.4 \pm 0.6$ & $29.01 \pm 0.65$ & $0.0458 \pm 0.0003$ & $0.203 \pm 0.002$ & $0.202 \pm 0.002$ & $0.303 \pm 0.002$ \\
\hline 16 & $0.155 \pm 0.003$ & $0.1924 \pm 0.0010$ & $76.6 \pm 0.3$ & $5.36 \pm 0.13$ & $0.0408 \pm 0.0007$ & $0.202 \pm 0.003$ & $0.203 \pm 0.003$ & $0.309 \pm 0.003$ \\
\hline 17 & $0.102 \pm 0.002$ & $0.2443 \pm 0.0010$ & $116.3 \pm 0.5$ & $2.72 \pm 0.07$ & $0.0401 \pm 0.0006$ & $0.203 \pm 0.004$ & $0.199 \pm 0.003$ & $0.309 \pm 0.003$ \\
\hline 18 & $0.130 \pm 0.003$ & $0.1893 \pm 0.0007$ & $101.1 \pm 0.5$ & $4.08 \pm 0.10$ & $0.0401 \pm 0.0008$ & $0.204 \pm 0.003$ & $0.198 \pm 0.003$ & $0.305 \pm 0.003$ \\
\hline 19 & $0.00161 \pm 0.00004$ & $0.2028 \pm 0.0074$ & $257 \pm 7$ & $0.19 \pm 0.01$ & $0.0392 \pm 0.0058$ & $0.199 \pm 0.015$ & $0.179 \pm 0.019$ & $0.316 \pm 0.020$ \\
\hline 20 & $0.088 \pm 0.002$ & $0.2102 \pm 0.0011$ & $93.6 \pm 0.4$ & $2.09 \pm 0.05$ & $0.0413 \pm 0.0009$ & $0.197 \pm 0.004$ & $0.199 \pm 0.004$ & $0.308 \pm 0.004$ \\
\hline 21 & $0.286 \pm 0.001$ & $0.1854 \pm 0.0011$ & $135.6 \pm 0.6$ & $7.32 \pm 0.18$ & $0.0391 \pm 0.0006$ & $0.201 \pm 0.002$ & $0.198 \pm 0.002$ & $0.305 \pm 0.002$ \\
\hline 22 & $0.0459 \pm 0.0009$ & $0.1862 \pm 0.0009$ & $91.7 \pm 0.5$ & $1.33 \pm 0.04$ & $0.0421 \pm 0.0011$ & $0.210 \pm 0.005$ & $0.207 \pm 0.004$ & $0.304 \pm 0.005$ \\
\hline 23 & $0.181 \pm 0.004$ & $0.1873 \pm 0.0008$ & $89.4 \pm 0.4$ & $4.33 \pm 0.11$ & $0.0398 \pm 0.0005$ & $0.201 \pm 0.003$ & $0.197 \pm 0.004$ & $0.313 \pm 0.003$ \\
\hline $24^{*}$ & $3.12 \pm 0.02$ & $0.1875 \pm 0.0009$ & $244 \pm 1$ & $60.40 \pm 1.48$ & $0.0388 \pm 0.0002$ & $0.198 \pm 0.001$ & $0.198 \pm 0.001$ & $0.301 \pm 0.001$ \\
\hline $25 *$ & $0.0495 \pm 0.0002$ & $0.1858 \pm 0.0009$ & $166.9 \pm 0.9$ & $0.91 \pm 0.02$ & $0.0405 \pm 0.0017$ & $0.211 \pm 0.004$ & $0.202 \pm 0.007$ & $0.312 \pm 0.006$ \\
\hline 26 & $0.057 \pm 0.001$ & $0.1878 \pm 0.0008$ & $84.6 \pm 0.4$ & $1.38 \pm 0.04$ & $0.0404 \pm 0.0010$ & $0.198 \pm 0.007$ & $0.205 \pm 0.006$ & $0.300 \pm 0.007$ \\
\hline 27 & $1.27 \pm 0.03$ & $0.1870 \pm 0.0009$ & $93.0 \pm 0.5$ & $27.52 \pm 0.69$ & $0.0397 \pm 0.0004$ & $0.196 \pm 0.002$ & $0.197 \pm 0.002$ & $0.302 \pm 0.003$ \\
\hline Total* & $7.86 \pm 0.05$ & $0.1947 \pm 0.0018$ & $92.2 \pm 0.8$ & $192 \pm 1$ & $0.0418 \pm 0.0005$ & $0.202 \pm 0.002$ & $0.200 \pm 0.002$ & $0.305 \pm 0.003$ \\
\hline Bulk & $153 \pm 4$ & $\mathrm{n} / \mathrm{a}$ & $3.47 \pm 0.02$ & $1352 \pm 69$ & $0.0397 \pm 0.0002$ & $0.200 \pm 0.001$ & $0.199 \pm 0.001$ & $0.310 \pm 0.002$ \\
\hline
\end{tabular}

${ }^{+}$Gas amounts in step 2 were very small and for the light, less abundant $\mathrm{Kr}$ and Xe isotopes the blank correction was large and contributes with up to $28 \%$ uncertainty for some isotopic

ratios.

*excluding steps 24 and 25 which suffered from atmospheric contamination (see main text) and the acid distill step 19. 
Table 4. Xenon concentrations and isotopic composition for all etch steps, total gas released in the CSSE analysis, and the bulk sample measured in the furnace

\begin{tabular}{|c|c|c|c|c|c|c|c|c|c|}
\hline Step & $\begin{array}{c}{ }^{132} \mathrm{Xe} \\
{\left[10^{-11} \mathrm{~cm}^{3} \mathrm{STP} / \mathrm{g}\right]}\end{array}$ & ${ }^{124} \mathrm{Xe} /{ }^{132} \mathrm{Xe}$ & ${ }^{126} \mathrm{Xe} /{ }^{132} \mathrm{Xe}$ & ${ }^{128} \mathrm{Xe} /{ }^{132} \mathrm{Xe}$ & ${ }^{129} \mathrm{Xe} /{ }^{132} \mathrm{Xe}$ & ${ }^{130} \mathrm{Xe} /{ }^{132} \mathrm{Xe}$ & ${ }^{131} \mathrm{Xe} /{ }^{132} \mathrm{Xe}$ & ${ }^{134} \mathrm{Xe} /{ }^{132} \mathrm{Xe}$ & ${ }^{136} \mathrm{Xe} /{ }^{132} \mathrm{Xe}$ \\
\hline 1 & $3.45 \pm 0.18$ & $0.00381 \pm 0.00010$ & $0.00328 \pm 0.00014$ & $0.0716 \pm 0.0011$ & $1.018 \pm 0.013$ & $0.152 \pm 0.002$ & $0.795 \pm 0.011$ & $0.389 \pm 0.006$ & $0.329 \pm 0.004$ \\
\hline 2 & $0.10 \pm 0.01$ & $0.00642 \pm 0.00122$ & $0.00401 \pm 0.00129$ & $0.0768 \pm 0.0045$ & $1.057 \pm 0.033$ & $0.146 \pm 0.007$ & $0.778 \pm 0.044$ & $0.398 \pm 0.033$ & $0.334 \pm 0.022$ \\
\hline 3 & $2.40 \pm 0.13$ & $0.00347 \pm 0.00014$ & $0.00350 \pm 0.00018$ & $0.0730 \pm 0.0013$ & $1.021 \pm 0.012$ & $0.152 \pm 0.002$ & $0.789 \pm 0.011$ & $0.394 \pm 0.007$ & $0.334 \pm 0.004$ \\
\hline 4 & $3.15 \pm 0.16$ & $0.00348 \pm 0.00019$ & $0.00374 \pm 0.00017$ & $0.0731 \pm 0.0014$ & $1.059 \pm 0.014$ & $0.154 \pm 0.002$ & $0.799 \pm 0.010$ & $0.401 \pm 0.006$ & $0.335 \pm 0.005$ \\
\hline 5 & $3.72 \pm 0.20$ & $0.00381 \pm 0.00014$ & $0.00362 \pm 0.00009$ & $0.0700 \pm 0.0009$ & $1.079 \pm 0.015$ & $0.150 \pm 0.002$ & $0.781 \pm 0.011$ & $0.380 \pm 0.006$ & $0.321 \pm 0.004$ \\
\hline 6 & $4.82 \pm 0.25$ & $0.00379 \pm 0.00013$ & $0.00344 \pm 0.00009$ & $0.0738 \pm 0.0011$ & $1.140 \pm 0.016$ & $0.155 \pm 0.002$ & $0.796 \pm 0.009$ & $0.387 \pm 0.006$ & $0.324 \pm 0.004$ \\
\hline 7 & $5.11 \pm 0.27$ & $0.00376 \pm 0.00013$ & $0.00349 \pm 0.00008$ & $0.0748 \pm 0.0011$ & $1.238 \pm 0.016$ & $0.154 \pm 0.002$ & $0.797 \pm 0.011$ & $0.392 \pm 0.006$ & $0.331 \pm 0.004$ \\
\hline 8 & $5.28 \pm 0.28$ & $0.00346 \pm 0.00011$ & $0.00334 \pm 0.00009$ & $0.0724 \pm 0.0010$ & $1.348 \pm 0.020$ & $0.151 \pm 0.002$ & $0.807 \pm 0.011$ & $0.392 \pm 0.005$ & $0.333 \pm 0.005$ \\
\hline 9 & $6.57 \pm 0.34$ & $0.00373 \pm 0.00011$ & $0.00348 \pm 0.00010$ & $0.0741 \pm 0.0010$ & $1.448 \pm 0.018$ & $0.152 \pm 0.002$ & $0.789 \pm 0.008$ & $0.388 \pm 0.005$ & $0.329 \pm 0.004$ \\
\hline 10 & $10.32 \pm 0.54$ & $0.00405 \pm 0.00009$ & $0.00363 \pm 0.00006$ & $0.0731 \pm 0.0007$ & $1.559 \pm 0.018$ & $0.153 \pm 0.001$ & $0.791 \pm 0.008$ & $0.387 \pm 0.004$ & $0.327 \pm 0.003$ \\
\hline 11 & $30.65 \pm 1.59$ & $0.00395 \pm 0.00006$ & $0.00376 \pm 0.00008$ & $0.0738 \pm 0.0006$ & $1.552 \pm 0.020$ & $0.152 \pm 0.001$ & $0.787 \pm 0.006$ & $0.381 \pm 0.003$ & $0.324 \pm 0.003$ \\
\hline 12 & $1.02 \pm 0.05$ & $0.00416 \pm 0.00036$ & $0.00374 \pm 0.00035$ & $0.0705 \pm 0.0013$ & $1.160 \pm 0.012$ & $0.153 \pm 0.002$ & $0.788 \pm 0.006$ & $0.384 \pm 0.009$ & $0.333 \pm 0.005$ \\
\hline 13 & $1.75 \pm 0.09$ & $0.00400 \pm 0.00024$ & $0.00427 \pm 0.00022$ & $0.0794 \pm 0.0013$ & $1.368 \pm 0.018$ & $0.156 \pm 0.003$ & $0.810 \pm 0.010$ & $0.390 \pm 0.005$ & $0.327 \pm 0.004$ \\
\hline 14 & $3.51 \pm 0.18$ & $0.00406 \pm 0.00007$ & $0.00370 \pm 0.00006$ & $0.0755 \pm 0.0012$ & $2.051 \pm 0.024$ & $0.156 \pm 0.001$ & $0.798 \pm 0.006$ & $0.385 \pm 0.004$ & $0.328 \pm 0.004$ \\
\hline 15 & $19.17 \pm 0.98$ & $0.00463 \pm 0.00006$ & $0.00464 \pm 0.00006$ & $0.0795 \pm 0.0008$ & $1.224 \pm 0.010$ & $0.157 \pm 0.001$ & $0.803 \pm 0.006$ & $0.389 \pm 0.003$ & $0.329 \pm 0.002$ \\
\hline 16 & $7.86 \pm 0.41$ & $0.00399 \pm 0.00010$ & $0.00365 \pm 0.00006$ & $0.0738 \pm 0.0009$ & $1.060 \pm 0.012$ & $0.157 \pm 0.002$ & $0.806 \pm 0.008$ & $0.391 \pm 0.005$ & $0.333 \pm 0.004$ \\
\hline 17 & $2.55 \pm 0.13$ & $0.00427 \pm 0.00019$ & $0.00427 \pm 0.00018$ & $0.0748 \pm 0.0010$ & $1.458 \pm 0.014$ & $0.154 \pm 0.002$ & $0.796 \pm 0.008$ & $0.388 \pm 0.004$ & $0.337 \pm 0.003$ \\
\hline 18 & $6.56 \pm 0.34$ & $0.00383 \pm 0.00009$ & $0.00350 \pm 0.00009$ & $0.0748 \pm 0.0007$ & $1.022 \pm 0.010$ & $0.157 \pm 0.001$ & $0.797 \pm 0.007$ & $0.390 \pm 0.005$ & $0.334 \pm 0.003$ \\
\hline 19 & $0.11 \pm 0.01$ & $0.00582 \pm 0.00067$ & $0.00699 \pm 0.00105$ & $0.0593 \pm 0.0065$ & $1.095 \pm 0.046$ & $0.177 \pm 0.011$ & $0.851 \pm 0.060$ & $0.349 \pm 0.019$ & $0.323 \pm 0.014$ \\
\hline 20 & $2.09 \pm 0.11$ & $0.00420 \pm 0.00014$ & $0.00371 \pm 0.00019$ & $0.0753 \pm 0.0015$ & $1.171 \pm 0.012$ & $0.157 \pm 0.002$ & $0.796 \pm 0.009$ & $0.387 \pm 0.005$ & $0.327 \pm 0.006$ \\
\hline 21 & $9.92 \pm 0.52$ & $0.00405 \pm 0.00007$ & $0.00349 \pm 0.00009$ & $0.0760 \pm 0.0009$ & $1.034 \pm 0.012$ & $0.156 \pm 0.002$ & $0.808 \pm 0.008$ & $0.389 \pm 0.004$ & $0.331 \pm 0.004$ \\
\hline 22 & $2.07 \pm 0.11$ & $0.00398 \pm 0.00032$ & $0.00394 \pm 0.00022$ & $0.0730 \pm 0.0016$ & $1.017 \pm 0.013$ & $0.152 \pm 0.002$ & $0.810 \pm 0.011$ & $0.385 \pm 0.005$ & $0.320 \pm 0.005$ \\
\hline 23 & $7.28 \pm 0.38$ & $0.00387 \pm 0.00008$ & $0.00355 \pm 0.00010$ & $0.0755 \pm 0.0009$ & $1.026 \pm 0.014$ & $0.155 \pm 0.002$ & $0.811 \pm 0.010$ & $0.391 \pm 0.006$ & $0.329 \pm 0.004$ \\
\hline 24 & $34.19 \pm 1.75$ & $0.00383 \pm 0.00006$ & $0.00361 \pm 0.00005$ & $0.0751 \pm 0.0009$ & $1.008 \pm 0.011$ & $0.155 \pm 0.001$ & $0.799 \pm 0.008$ & $0.404 \pm 0.004$ & $0.327 \pm 0.004$ \\
\hline 25 & $0.77 \pm 0.04$ & $0.00451 \pm 0.00032$ & $0.00404 \pm 0.00025$ & $0.0790 \pm 0.0017$ & $1.027 \pm 0.014$ & $0.159 \pm 0.004$ & $0.814 \pm 0.013$ & $0.375 \pm 0.011$ & $0.317 \pm 0.005$ \\
\hline 26 & $1.41 \pm 0.07$ & $0.00468 \pm 0.00019$ & $0.00402 \pm 0.00013$ & $0.0788 \pm 0.0017$ & $1.050 \pm 0.010$ & $0.156 \pm 0.001$ & $0.807 \pm 0.012$ & $0.378 \pm 0.008$ & $0.325 \pm 0.004$ \\
\hline 27 & $26.01 \pm 1.34$ & $0.00433 \pm 0.00009$ & $0.00398 \pm 0.00005$ & $0.0786 \pm 0.0009$ & $1.044 \pm 0.017$ & $0.159 \pm 0.002$ & $0.807 \pm 0.009$ & $0.387 \pm 0.004$ & $0.326 \pm 0.004$ \\
\hline Total* & $167 \pm 3$ & $0.00406 \pm 0.00003$ & $0.00380 \pm 0.00003$ & $0.0754 \pm 0.0005$ & $1.256 \pm 0.009$ & $0.155 \pm 0.001$ & $0.799 \pm 0.005$ & $0.387 \pm 0.002$ & $0.328 \pm 0.002$ \\
\hline Bulk & $1662 \pm 85$ & $0.00460 \pm 0.00006$ & $0.00407 \pm 0.00004$ & $0.0817 \pm 0.0008$ & $1.047 \pm 0.012$ & $0.161 \pm 0.001$ & $0.820 \pm 0.007$ & $0.381 \pm 0.004$ & $0.322 \pm 0.003$ \\
\hline
\end{tabular}

*excluding steps 24 and 25 which suffered from atmospheric contamination (see main text) and the acid distill step 19. 

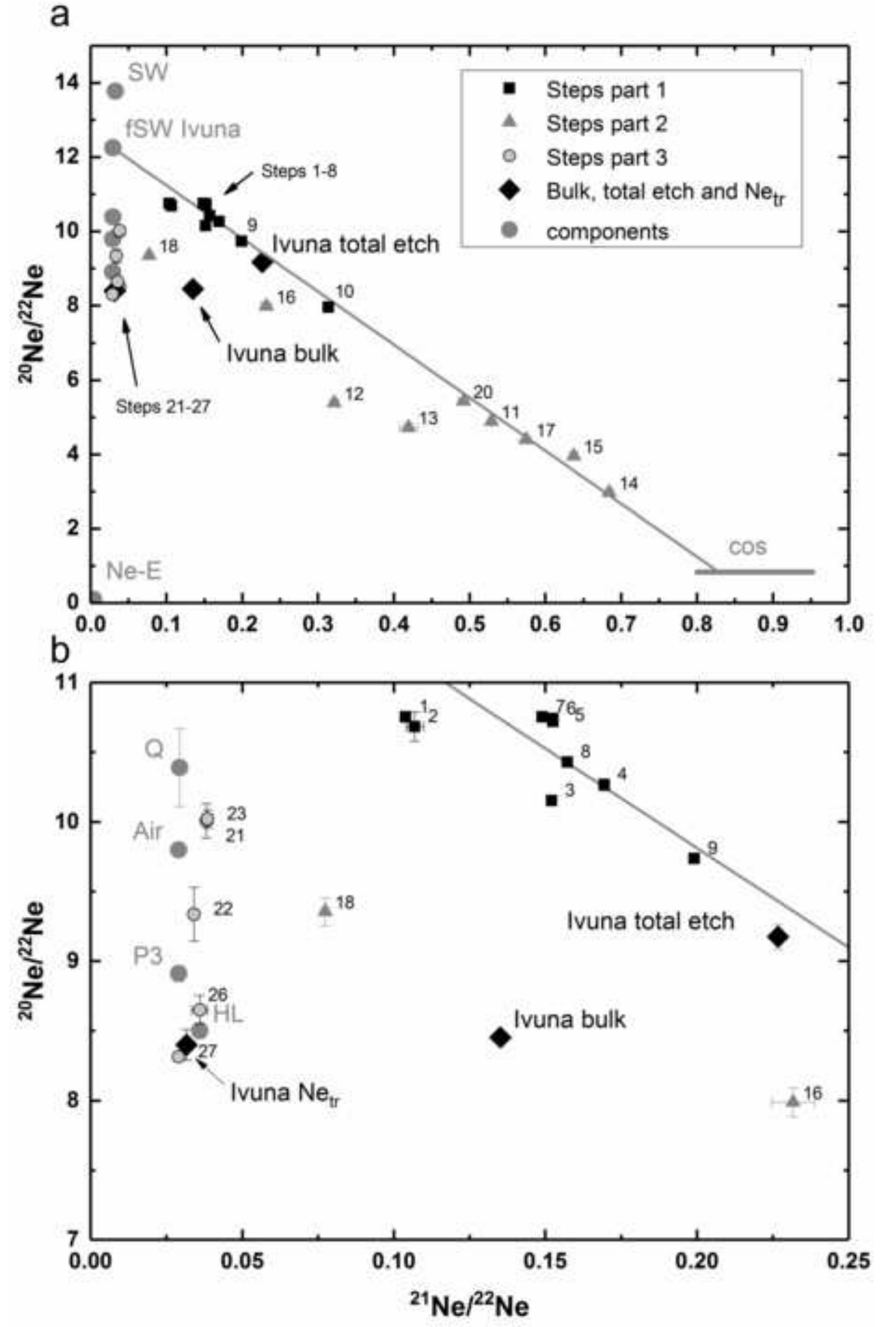

Figure

. 


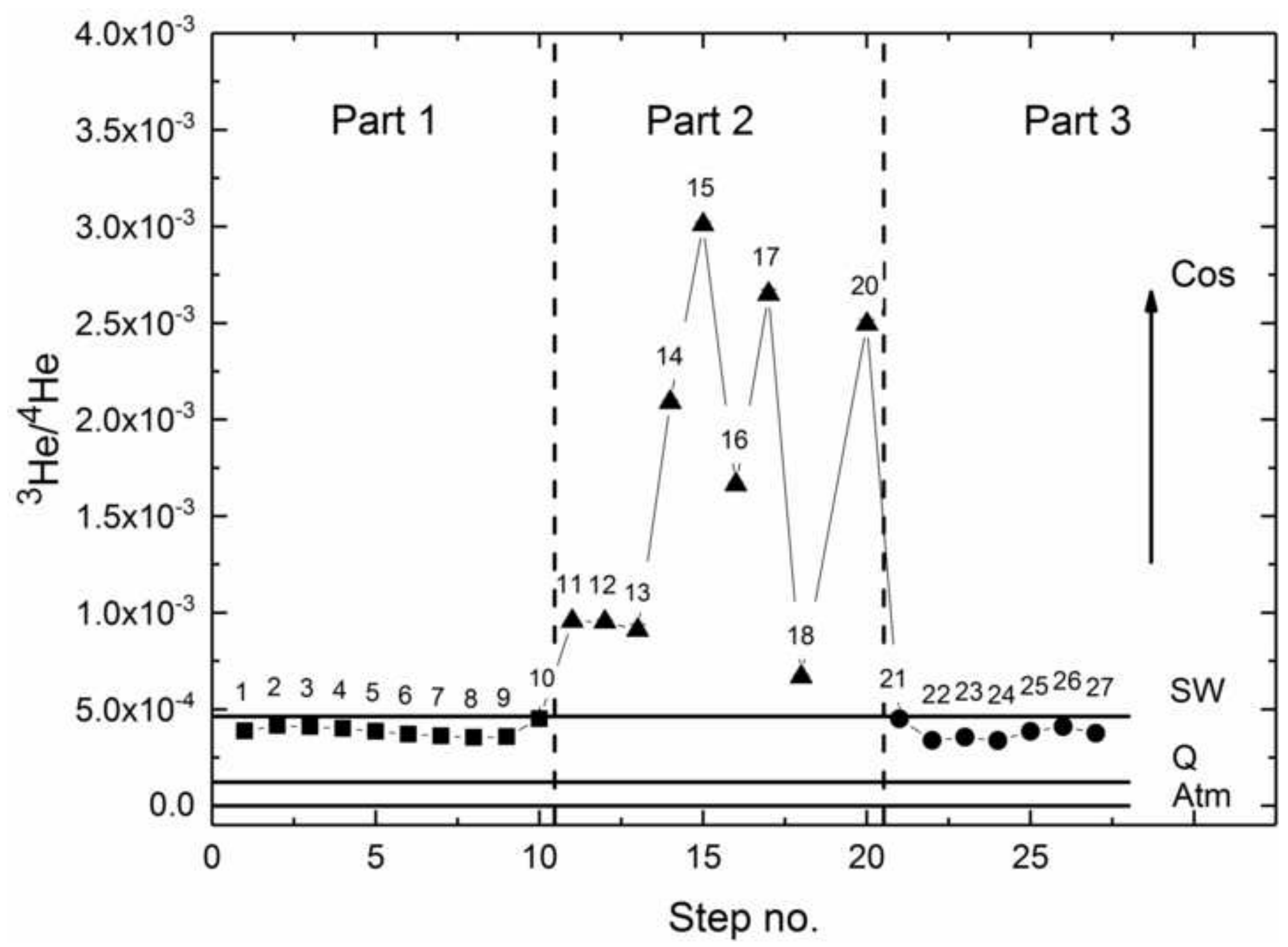



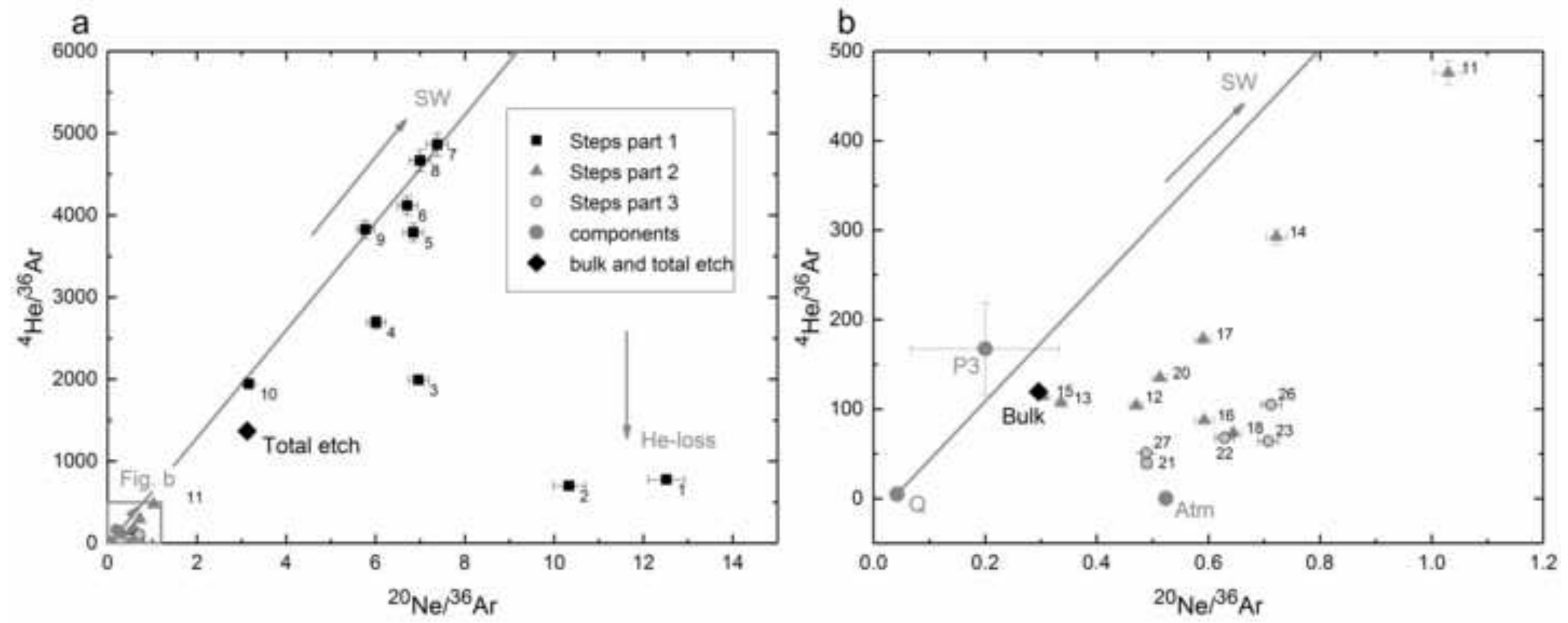

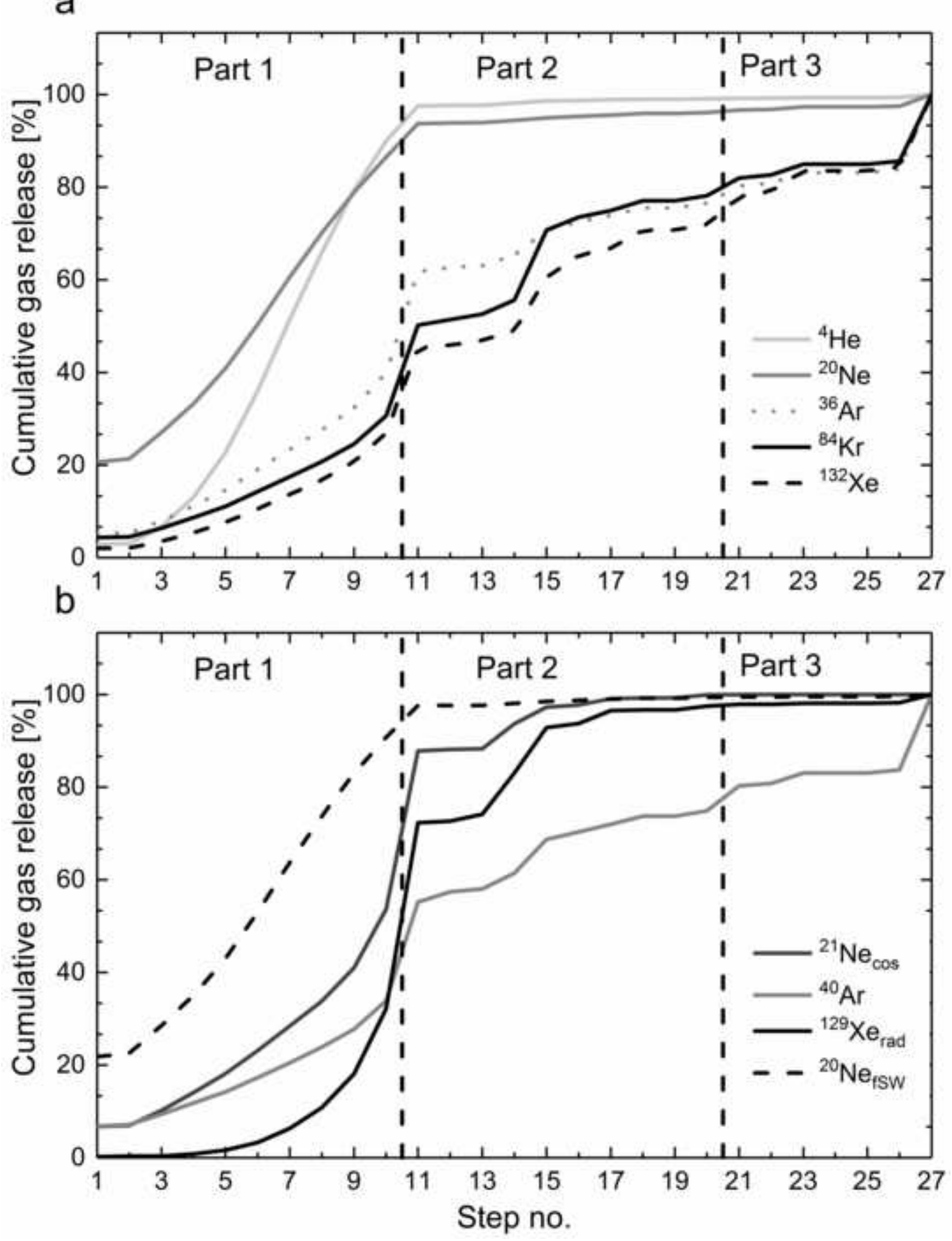


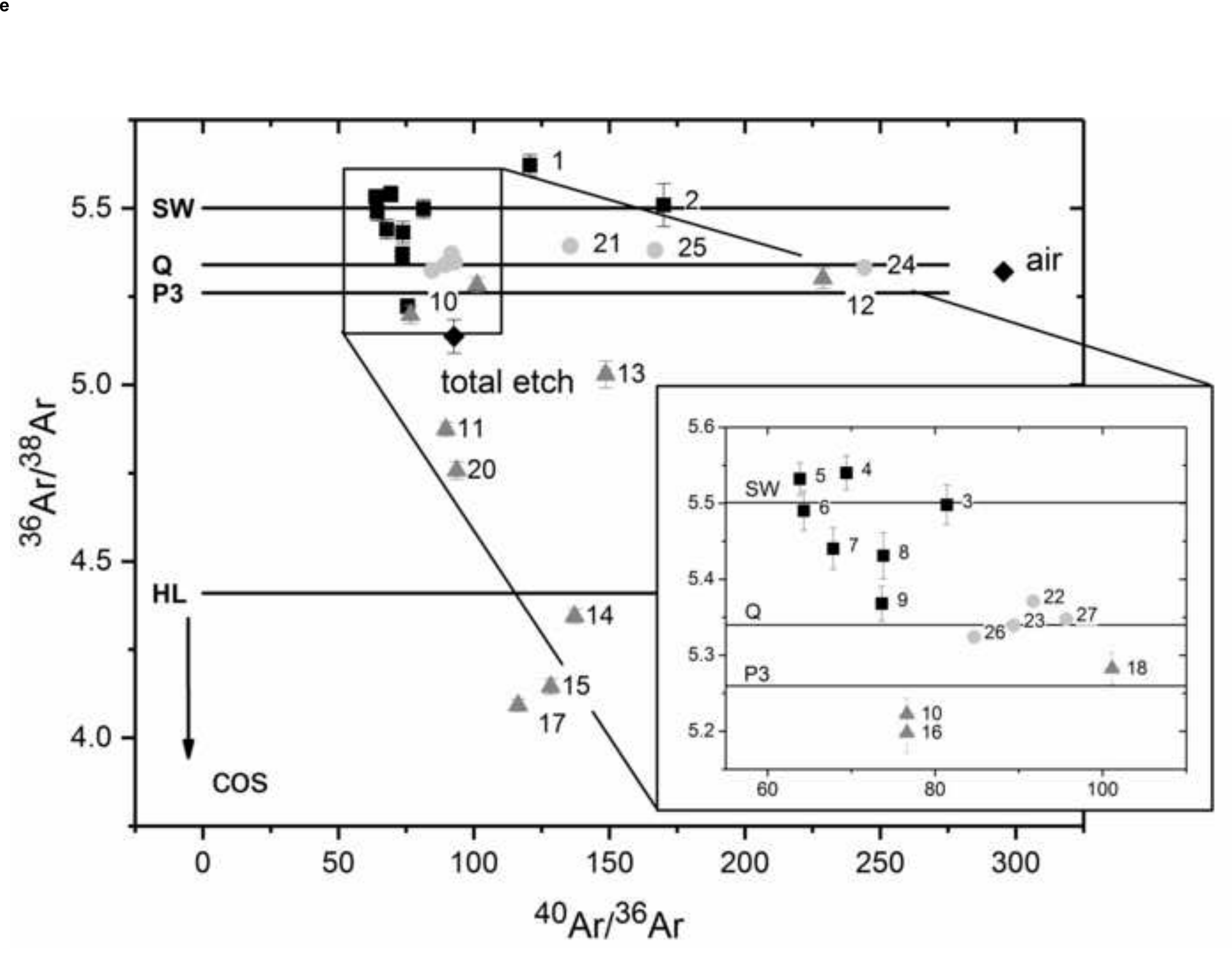



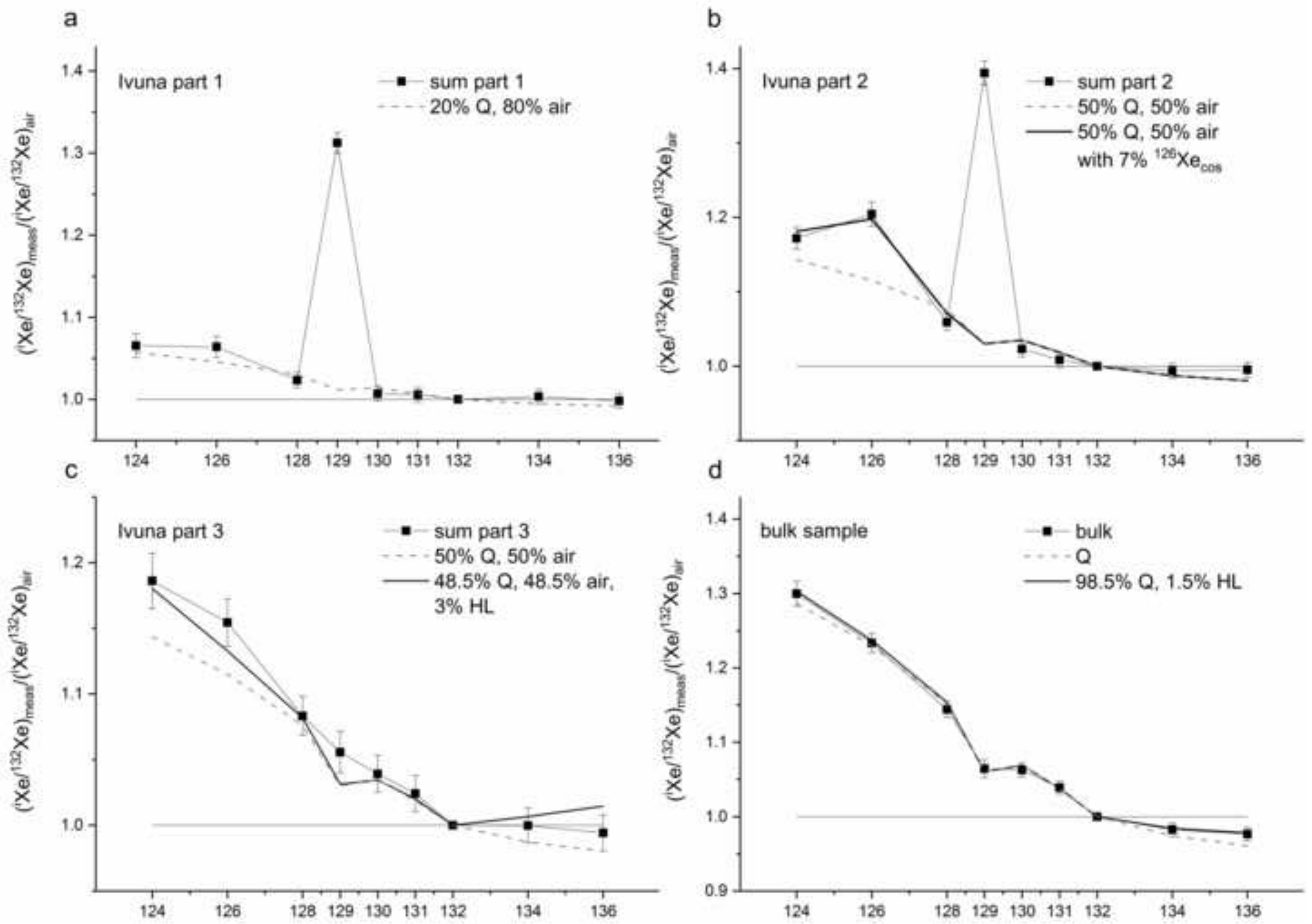


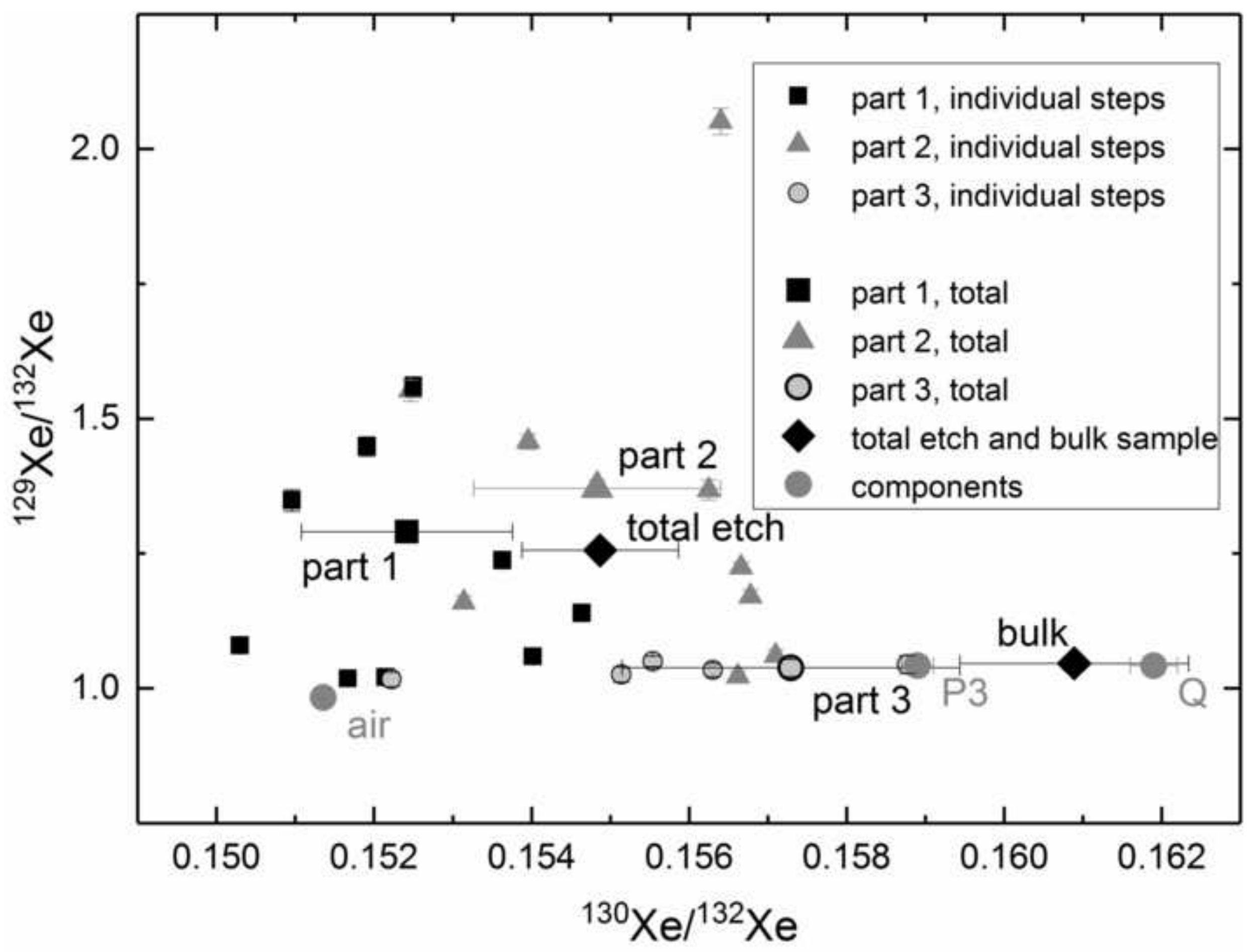

